\title{
Current research activities in the field of multilayers for soft X-rays in Japan
}

\author{
T. Namioka \\ Research Institute for Scientific Measurements, Tohoku University, Sendai 980, Japan
}

(Reçu le 29 septembre 1987, accepté le 8 février 1988)

\begin{abstract}
Résumé. - Les programmes en cours de développement au Japon sont passés brièvement en revue. Les thèmes d'études examinés portent sur les principes des optiques envisagées et sur quelques applications, les études de constantes optiques X-UV des substrats et des films minces ainsi que sur les techniques d'évaporation.
\end{abstract}

\begin{abstract}
The present status of studies on soft X-ray multilayers in Japan is briefly reviewed. This includes the design concepts, optical constants of substrates and thin films, fabrication techniques, evaluation methods, and some applications.
\end{abstract}

\section{Introduction.}

Studies of multilayers in Japan are relatively new in the field of soft X-ray optics, in striking contrast to extensive research in the field of semiconductors. Our current efforts have thus been directed more to basic research, both academic and technical, than applications, though those researches are all aimed at specific applications.

This paper describes, as a representative example, the current activities of several Japanese research groups in the field of multilayers for soft X-ray optics. This includes various design concepts, examples of designed multilayers, measurement of optical constants, fabrication of substrates and multilayers, evaluation of roughness, entrapped Ar, crystal structure, and reflectance, and applications to X-ray lithography and X-ray telescopes. The groups participating in this paper are listed below.

Tohoku group : T. Namioka, M. Yamamoto, M. Yanagihara, and A. Arai, Research Institute for Scientific Measurements, Tohoku University (Katahira, Sendai 980) ;

Photon Factory (PF) group: T. Matsushita, A. Iida, and T. Ishikawa, Photon Factory, National Laboratory for High Energy Physics (Oho, Tsukuba-shi, Ibaraki 305) ;

Yoshida Nano-Mechanism Project (YNMP) group: S. Yoshida, H. Nagata, and Y. Suzuki, JRDC (2-5-2 Marunouchi, Chiyoda-ku, Tokyo 100) ;
NTT group: Y. Ishii, $H$. Takenaka, and $H$. Takaoka, NTT Electrical Communication Laboratory (3-9-11 Midori-machi, Musashino-shi, Tokyo 180) ;

H. Kinoshita, T. Kaneko, H. Takei, N. Takeuchi, and T. Ishihara, NTT Atsugi Electrical Communication Laboratory (1839 Ono, Atsugi-shi, Kanagawa 243-01) ;

Canon group : S. Ogura and Y. Watanabe, Canon Research Center, Canon Inc. (5 MorinosatoWakamiya, Atsugi-shi, Kanagawa 243-01) ;

Nagoya group : F. Nagase, H. Kunieda, Y. Tawara, and T. Kii, Dept. of Astrophysics, Nagoya University (Chikusa-ku, Nagoya 464) ;

Chubu group: Y. Namba, Chubu University (Kasugai, Aichi 487);

Kyoto group : T. Shinjo, N. Nakayama, and I. Moritani, Institute for Chemical Research, Kyoto University (Uji, Kyoto 611) ;

Osaka group I : K. Yamashita, H. Tsunemi, S. Kitamoto, I. Hatsukade, A. Miyake, and Y. Ueno, Dept. of Physics, Osaka University (Toyonaka, Osaka 560) ;

Osaka group II : Y. Kato, H. Shiraga, K. Shihoyama, and T. Endoh, Institute of Laser Engineering, Osaka University (Suita, Osaka 565) ;

Kwansei-Gakuin group : H. Terauchi, N. Sano, H. Kato, M. Nakayama, Y. Nishihata, and K. Kamigaki, Dept. of Physics, Kwansei-Gakuin University (Uegahara, Nishinomiya 662). 


\section{Design of multilayers.}

2.1 Periodic MUltilayers. - In designing multilayers the first thing we have to do is to choose a proper pair of materials for a specific purpose. YNMP group, who is interested in developing X-ray microscopes and X-ray lithography devices for wavelengths of $10-50 \AA$, calculated the saturated reflectance at normal incidence of periodic multilayers, consisting of various pair materials $\mathrm{A}$ and B, by using formulas based on Fresnel equations [13] with the optical constants derived from the data of Henke et al. [4]. The result obtained for a wavelength of $25.2 \AA$ is summarized in table I.

Table I shows that combinations of any material in the group of $\mathrm{Ni}, \mathrm{Co}, \mathrm{Cu}, \mathrm{Fe}, \mathrm{Re}, \mathrm{Zn}, \mathrm{W}, \mathrm{Mn}, \mathrm{Ta}$ and $\mathrm{Au}$ with any one in the group of $\mathrm{Be}, \mathrm{Mg}, \mathrm{Sn}, \mathrm{Sb}, \mathrm{V}$ and $\mathrm{Te}$ would provide relatively high reflectance and that among them the $\mathrm{Ni} / \mathrm{Be}$ combination would give the highest reflectance of $44.5 \%$. It is interesting to note in the table that the multilayers containing V ( $L$ absorption edge at $24.03 \AA$ ), Sn ( $M$ edge at $24.03 \AA$ ), or Sb ( $M$ edge at $23.44 \AA$ ) show relatively high reflectances at $25.2 \AA$, even though their atomic numbers are not small. This is due to the effect of anomalous dispersion, which causes a large difference in the refractive indices of the two materiais and reduces the amount of absorption.

Figure 1 shows some examples of the enhancement in reflectances due to this effect. The spectral reflectances of all the multilayers at normal incidence were calculated by keeping the total thickness of the multilayers to a constant value of $3660 \AA$. This clearly illustrates the usefulness of a material whose absorption edge lies at a wavelength slightly shorter than the design wavelength. An experimental proof of this idea is given in section 5.2.

With a pair of materials thus chosen, a further increase in the reflectance would be possible by controlling the density of the materials. Figure 2 compares the calculated reflectances at the 45-deg. angle of incidence of a 128-pair W/C multilayer with and without density control in the $\mathrm{C}$ layers. The carbon density is assumed to be $80 \%$ of the bulk value in the controlled case. As is seen in the figure, the peak reflectance of the density-controlled multilayer is 1.3 times higher than that of the noncontrolled one. Similar results were obtained for multilayers of other combinations in different wavelength ranges, suggesting the possibility of increasing the reflectance by means of density control.

Table I. - Saturated reflectances (\%) of multilayers composed of two materials A and B. Reflectances are computed for a wavelength of $25.2 \AA$ (courtesy of YNMP group).

\begin{tabular}{|c|c|c|c|c|c|c|c|c|c|c|c|c|c|c|c|c|c|c|c|c|c|}
\hline & \multicolumn{20}{|c|}{ A } \\
\hline & & $\mathrm{Mn}$ & $\mathrm{Fe}$ & Co & $\mathrm{Ni}$ & $\mathrm{Cu}$ & $\mathrm{Zn}$ & $\mathrm{Ga}$ & As & $\mathrm{Nb}$ & Mo & $\mathrm{Tc}$ & $\mathrm{Ru}$ & $\mathrm{Pd}$ & $\mathrm{Hf}$ & Ta & W & $\mathrm{Re}$ & $\mathrm{Au}$ & Ho & $\mathrm{Er}$ \\
\hline & $\mathrm{Be}$ & 31.9 & 37.1 & 42.5 & 44.5 & 40.4 & 34.0 & 25.4 & 22.7 & 24.1 & 25.8 & 28.1 & 26.6 & 24.8 & 26.7 & 31.3 & 33.9 & 35.5 & 31.1 & 22.0 & 20.8 \\
\hline & B & 11.9 & 17.5 & 23.9 & 26.7 & 22.9 & 16.4 & 9.1 & 7.9 & 12.0 & 13.9 & 16.3 & 15.5 & 14.0 & 13.9 & 18.3 & 21.0 & 22.6 & 18.8 & 8.7 & 8.3 \\
\hline & C & & 12.6 & 17.8 & 20.2 & 16.9 & 11.5 & 5.8 & 4.8 & 7.7 & 9.3 & 11.4 & 10.7 & 9.4 & 9.4 & 13.1 & 15.5 & 16.9 & 13.6 & 5.2 & 4.9 \\
\hline & $\mathrm{Mg}$ & 27.4 & 36.3 & 41.1 & 42.8 & 38.9 & 32.9 & 24.9 & 22.0 & 22.5 & 24.0 & 26.0 & 24.4 & 22.7 & 25.0 & 29.3 & 31.8 & 33.4 & 29.0 & 20.9 & 19.7 \\
\hline & $\mathrm{Si}$ & 12.4 & 17.7 & 23.6 & 26.3 & 22.6 & 16.3 & 9.2 & 8.0 & 11.5 & 13.3 & 15.6 & 14.7 & 13.3 & 13.4 & 17.7 & 20.3 & 21.8 & 18.1 & 8.5 & 8.1 \\
\hline & $S$ & & 16.3 & 21.2 & 23.4 & 19.9 & 14.6 & 8.5 & 7.1 & 9.1 & 10.6 & 12.5 & 11.6 & 10.3 & 10.9 & 14.6 & 16.9 & 18.3 & 14.9 & 7.0 & 6.5 \\
\hline & $\mathrm{Ca}$ & & & 24.4 & 25.9 & 22.4 & 17.9 & 12.7 & 10.6 & 9.6 & 10.5 & 11.9 & 10.6 & 9.4 & 11.4 & 14.5 & 16.4 & 17.6 & 14.2 & 9.3 & 8.3 \\
\hline & V & 28.9 & 32.3 & 36.2 & 37.7 & 33.7 & 28.6 & 22.0 & 19.2 & 17.6 & 18.6 & 20.2 & 18.5 & 16.9 & 19.9 & 23.5 & 25.7 & 27.1 & 22.9 & 17.3 & 16.0 \\
\hline & $\mathrm{Sr}$ & & & 20.7 & 22.4 & 19.1 & 14.4 & 9.2 & 7.5 & 8.0 & 9.1 & 10.7 & 9.7 & 8.5 & 9.6 & 12.9 & 14.9 & 16.2 & 12.9 & 6.8 & 6.1 \\
\hline & Sn & 34.9 & 36.6 & 38.8 & 39.6 & 35.8 & 31.9 & 27.1 & 23.7 & 18.5 & 18.6 & 19.3 & 17.2 & 15.9 & 20.5 & 23.2 & 24.7 & 25.9 & 21.9 & 20.5 & 18.8 \\
\hline & $\mathrm{Sb}$ & 30.7 & 33.1 & 36.0 & 37.1 & 33.3 & 28.8 & 23.3 & 20.3 & 16.8 & 17.3 & 18.4 & 16.5 & 15.2 & 18.9 & 21.9 & 23.8 & 25.1 & 21.0 & 17.7 & 16.2 \\
\hline & $\mathrm{Te}$ & 28.3 & 31.1 & 34.4 & 35.7 & 31.8 & 27.1 & 21.3 & 18.4 & 15.9 & 16.6 & 17.9 & 16.2 & 14.8 & 18.0 & 21.3 & 23.2 & 24.6 & 20.6 & 16.2 & 14.9 \\
\hline & $\mathrm{La}$ & & 13.7 & 18.9 & 21.4 & 18.0 & 12.5 & 6.5 & 5.5 & 8.3 & 10.0 & 12.1 & 11.3 & 10.0 & 10.0 & 13.8 & 16.3 & 17.7 & 14.3 & 5.8 & 5.5 \\
\hline
\end{tabular}




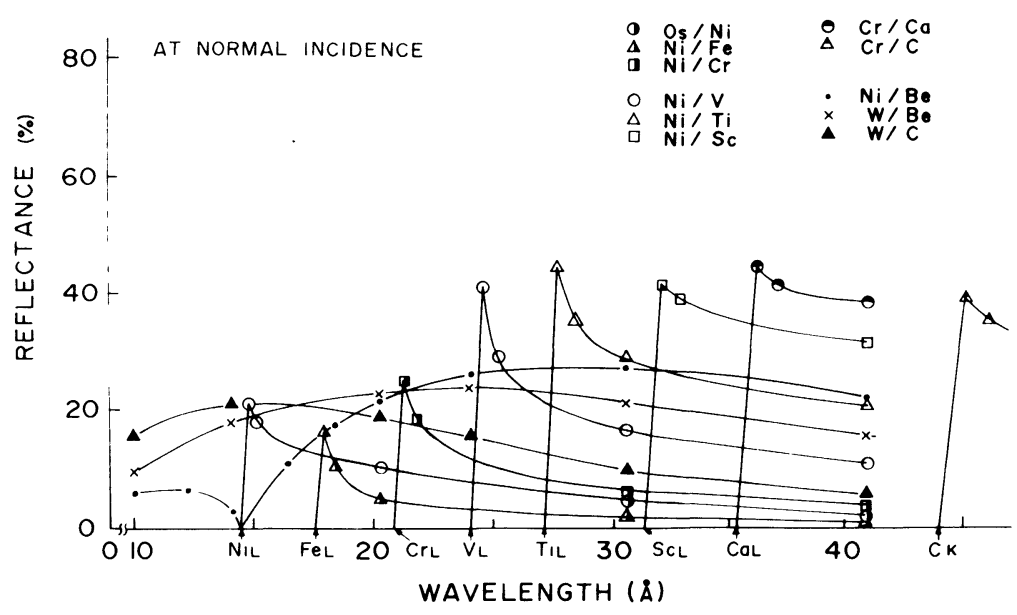

Fig. 1. - Calculated reflectance of multilayers which utilize anomalous dispersion at the X-ray absorption edge. The total thickness of the multilayers is assumed to be $3660 \AA$ (courtesy of YNMP group).

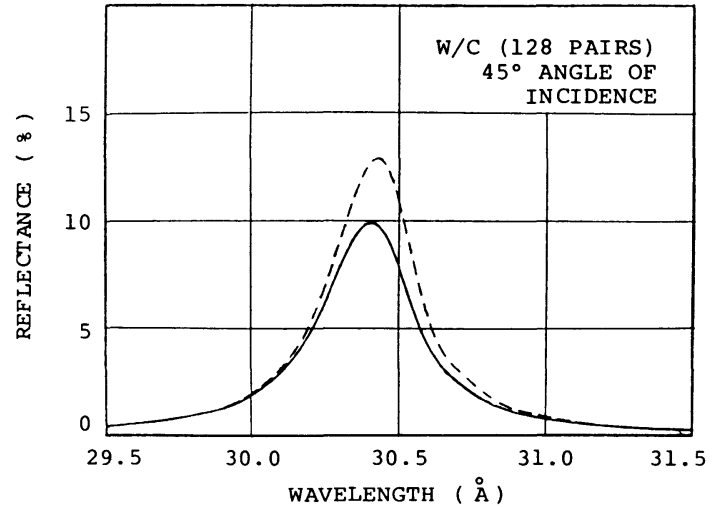

Fig. 2. - Calculated reflectances of $\mathrm{W} / \mathrm{C}$-multilayers with and without density control. The solid line is the reflectance calculated with the bulk densities and the dashed line is the reflectance when the carbon density is assumed to be $80 \%$ of the bulk density (courtesy of YNMP group).

2.2 APERIODIC MUlTilayers. - Tohoku group has developed a new design method of multilayers utilizing a Gaussian-plane plot of the complex amplitude reflectance [5]. Reformulating a well known recurrence formula [1], they derived the following formula for the complex amplitude reflectance $R_{m}$ of a $m$-layer system in a vacuum :

$R_{m}=\frac{r_{m}\left(1-r_{m} R_{m-1}\right)+\left(R_{m-1}-r_{m}\right) \exp \left(-i \delta_{m}\right)}{1-r_{m} R_{m-1}+r_{m}\left(R_{m-1}-r_{m}\right) \exp \left(-i \delta_{m}\right)}$,
$m=1,2, \ldots, m, \quad$ (1)

where

$\delta_{m}=4 \pi n_{m} d_{m} \cos \phi_{m} / \lambda$,

$R_{0}=r_{0}$ (for the substrate),(2)

$r_{m}$ is the Fresnel reflection coefficient of the $m$-th layer material with respect to the vacuum, $n_{m}\left(=n_{m}-i k_{m}\right)$ the complex refractive index of the $m$-th layer material, $d_{m}$ the thickness of the $m$-th layer, $\phi_{m}$ the angle of refraction into the $m$-th layer, and $\lambda$ the wavelength of incident light.

A graphical representation of equation (1) enables one to visualize the changes in the amplitude reflectance with the growth of layered structure, giving a clear insight into the multilayer design. A typical example of such a representation in the complex plane is given in figure 3. Points $r_{\mathrm{S}}, r_{\mathrm{A}}$, and $r_{\mathrm{B}}$ represent the Fresnel reflection coefficients of the substrate, material $\mathrm{A}$, and material $\mathrm{B}$ with respect to the vacuum respectively. Suppose we start, in figure 3, deposition of $\mathrm{A}$ on the substrate. As the deposition proceeds, i.e., as the layer thickness $d_{1}$ increases, the amplitude reflectance $R_{1}\left(d_{1}\right)$ starts to move from $r_{\mathrm{S}}$ and spirals in toward $r_{\mathrm{A}}$, producing

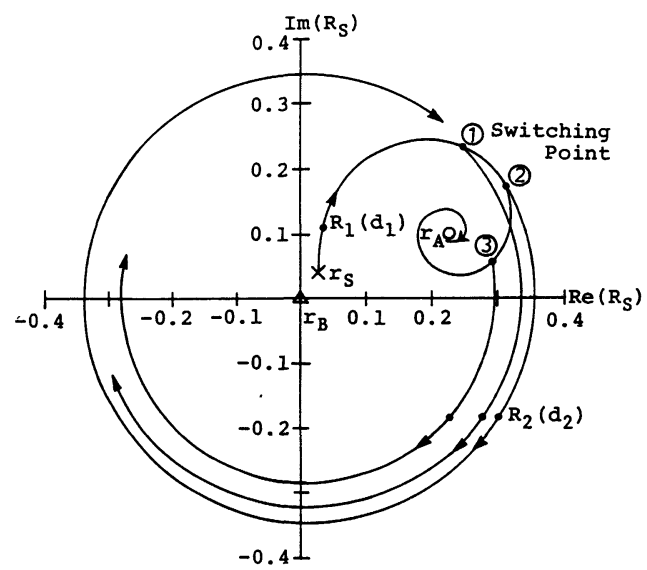

Fig. 3. - Growth of the complex amplitude reflectance $R_{\mathrm{s}}$ during the formation of the first two layers of a multilayer consisting of materials $\mathrm{A}\left(n_{\mathrm{A}}=0.65-0.12 \mathrm{i}\right)$ and B $\quad\left(n_{\mathrm{B}}=0.99-0.0046 \mathrm{i}\right) . \quad \mathrm{A}$ glass substrate $\left(n_{\mathrm{S}}=0.947-0.08 \mathrm{i}\right), 15-\mathrm{deg}$. angle of incidence, and $210 \AA$ incident light are assumed. 
the reflectance maxima and minima alternately. To increase the reflectance it is necessary to switch the deposition of A over to that of B at a certain stage of growth. If this is done, then the amplitude reflectance $R_{2}\left(d_{2}\right)$ of the bi-layer spirals in toward $r_{\mathrm{B}}$ as the thickness $d_{2}$ of the second layer increases, and its course depends solely on its starting point, at which the deposition of A was switched over to that of B (see Fig. 3). In view of this, one can see that a highly reflective multilayer can be realized effectively by choosing switching points properly so as to make a series of amplitude reflectance curves to expand outward most efficiently as the multilayer structure grows. It can be shown that the optimum multilayer structure that gives the highest reflectance for a given pair of materials is realized by switching the deposition of materials at the points where the successive amplitude reflectance curves connect smoothly.

Table II compares, for a pair of $\mathrm{Re}$ and $\mathrm{Al}$, the reflectance of an optimum aperiodic multilayer with that of an optimized periodic multilayer as a function of the number of layers. The reflectance increases much faster for the aperiodic structure as compared with the periodic one, especiaily for the first 11 layers or so. The difference, however, becomes smaller as the number of layer increases.

Table II. - Comparison of calculated reflectances of an optimum aperiodic $\mathrm{Re} / \mathrm{Al}$ multilayer with those of an optimized periodic one.

\begin{tabular}{|c|c|c|c|c|c|c|}
\hline \multirow{3}{*}{$m$} & \multicolumn{2}{|c|}{ Periodic } & \multicolumn{3}{|c|}{ Aperiodic } & \multirow{3}{*}{$\Delta R$} \\
\hline & \multirow{2}{*}{$\begin{array}{c}d(\AA) \\
\mathrm{Al}, \quad \operatorname{Re}\end{array}$} & \multirow[t]{2}{*}{$R(\%)$} & \multicolumn{2}{|r|}{$d(\AA)$} & \multirow[t]{2}{*}{$R(\%)$} & \\
\hline & & & $\mathrm{Al}$, & $\operatorname{Re}$ & & \\
\hline 1 & - , 28.3 & 6.01 & - & (72.4) 74.0 & 12.68 & 6.97 \\
\hline 3 & $85.6, \quad 28.3$ & 17.17 & 62.0 , & (58.7) 58.0 & 29.79 & 12.62 \\
\hline 5 & ditto & 28.50 & 68.0 , & 47.0 & 41.62 & 13.12 \\
\hline 7 & & 37.97 & 72.7, & 40.5 & 49.62 & 11.23 \\
\hline 9 & & 45.27 & 76.1, & 36.0 & 54.10 & 8.83 \\
\hline 11 & & 50.68 & 78.6, & 33.5 & 57.34 & 6.66 \\
\hline 13 & & 54.61 & 80.4, & (32.6) 34.0 & 59.47 & 4.86 \\
\hline 15 & & 57.44 & 81.6, & 30.0 & 61.00 & 3.56 \\
\hline 17 & & 59.47 & 82.5 , & 29.0 (30.4) & 62.04 & 2.57 \\
\hline 19 & & 60.92 & 83.1, & 29.0 (29.8) & 62.77 & 1.85 \\
\hline
\end{tabular}

This graphical representation of equation (1) is also useful in the selection of a material pair and a protective overcoating material, the development of a tandem multilayer and a multilayer composed of multielements, and the design of optical elements such as a multilayer-coated grating, a wide-band mirror, a polarizer, a band-pass filter, a beam splitter, etc.

\section{Measurement of optical constants.}

It is extremely important in the design of multilayers to have accurate optical constants of materials in the soft X-ray region. An effort has, therefore, been made by Tohoku group to measure the optical constants of substrate materials and of thin films, using synchrotron radiation at the Photon Factory.

3.1 OPTICAL CONSTANTS OF SUBSTRATE MATERIALS, - Yanagihara et al. [6] designed and installed a high-precision UHV reflectometer on beamline $11 \mathrm{~A}$ at the Photon Factory. Figure 4 is a schematic of the reflectometer. The reflectometer is constructed in such a way that alignment of the rotation axes of the sample and the detector remains unaffected when it is evacuated and/or baked. The accuracy of the sample rotation and detector rotation was found to be better than $30 \mathrm{~s}$ of arc. Reflectance measurement can be done at any angle of incidence in a range $9.6-89.4 \mathrm{deg}$.

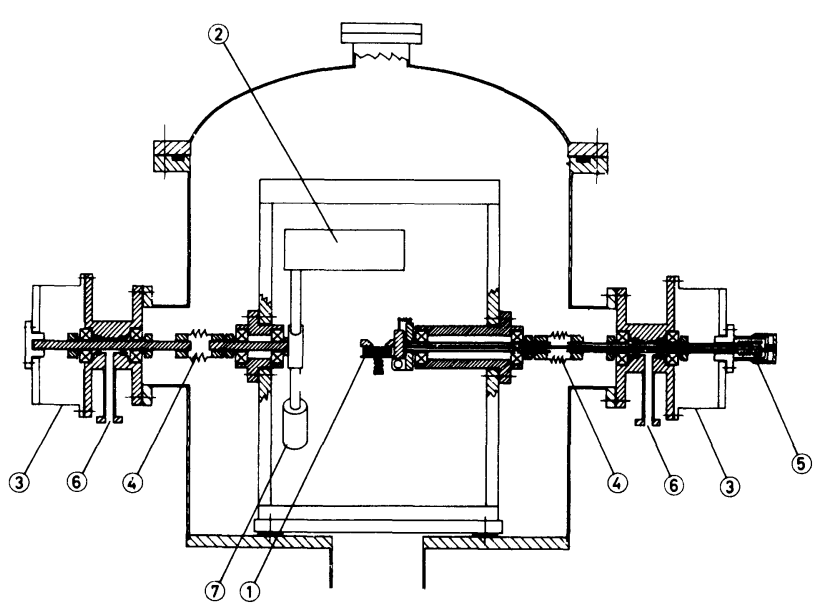

Fig. 4. - Schematic diagram of reflectometer. (1), sample ; (2), detector ; (3), goniometer ; (4), bellows coupling ; (5), linear motion feedthrough ; (6), differential pumping port ; (7), counterbalance (after Ref. [6]).

Using the reflectometer together with a 2-m grasshopper monochromator, Yanagihara et al. measured the reflectances of polished CVD-SiC (samples I and II), CVD-TiC, and sintered-WC mirrors at photon energies of $80-1200 \mathrm{eV}$. In the analysis the Debye-Ŵaller factor was taken into consideration. In figure 5 is shown a typical example of $R-\theta$ plots ( $R:$ reflectance, $\theta:$ angle of incidence) obtained for the CVD-SiC mirror (sample I). Errors in the observed reflectances are less than $3 \%$. The optical constants $\delta(=1-n)$ and $k$ were determined by means of curve fitting to the measured reflectance curves (see solid lines in Fig. 5). Their values are listed in table III together with the rms surface roughness $\sigma$ in the Debye-Waller factor. These $\sigma$ 


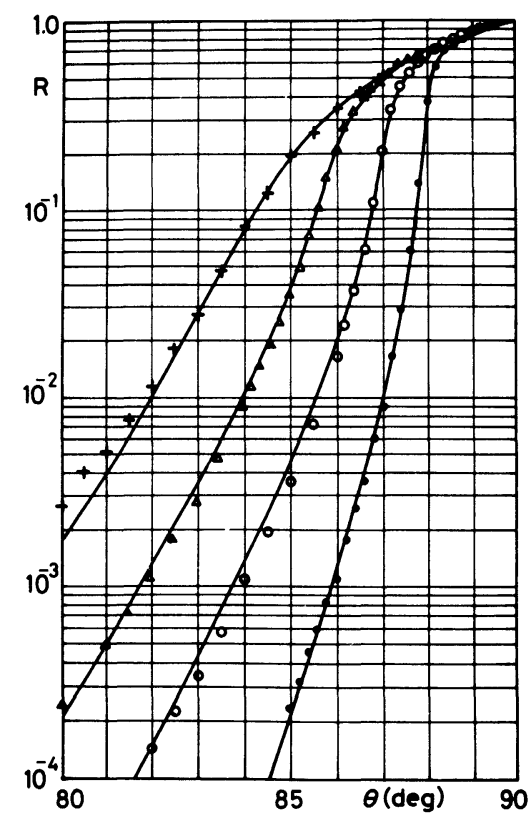

Fig. 5. - Measured reflectance as a function of incidence angle for polished CVD-SiC (sample I) at $h \nu=1000 \mathrm{eV}$ $(\bullet), 700 \mathrm{eV}(O), 500 \mathrm{eV}(\triangle)$, and $350 \mathrm{eV}(+)$. Solid lines are calculated values (after Ref.[6]).

Table III. - Optical constants of $\mathrm{SiC}$ in the soft $X$ ray region. $\sigma$ is the rms roughness (after Ref. [6]).

\begin{tabular}{|r|l|l|l|}
\hline$E(\mathrm{eV})$ & $\delta=1-n$ & $k$ & $\sigma(\AA)$ \\
\hline Sample I & & & \\
80 & 0.0337 & $1.28 \mathrm{E}-2$ & 33.8 \\
100 & 0.00718 & $4.09 \mathrm{E}-3$ & 18.1 \\
120 & 0.00753 & $1.58 \mathrm{E}-2$ & 28.3 \\
150 & 0.0116 & $1.39 \mathrm{E}-2$ & 28.0 \\
200 & 0.00934 & $6.47 \mathrm{E}-3$ & 27.5 \\
250 & 0.00729 & $5.03 \mathrm{E}-3$ & 29.6 \\
\hline Sample II & & & \\
350 & 0.00488 & $2.33 \mathrm{E}-3$ & 22.9 \\
500 & 0.00253 & $6.45 \mathrm{E}-4$ & 18.0 \\
700 & 0.00129 & $2.06 \mathrm{E}-4$ & 15.0 \\
1000 & 0.00062 & $4.30 \mathrm{E}-5$ & 17.2 \\
\hline
\end{tabular}

values obtained at different photon energies are consistent with one another for the same sample and the averaged value of $28 \AA$ for sample II is in good agreement with a value of $23 \AA$ measured with a WYKO profiler. This result, together with those for the CVD-TiC and WC mirrors, suggests that the simple diffractive scattering model is applicable even to the case of specular reflections of soft X-rays from rough surfaces that violate the assumption $\lambda \gg \sigma$. The reason for this is not clear at the present.

Tohoku group [7] determined also the optical constants of polished BK7 glass in a wavelength range 120-200 $\AA$ using the same reflectometer.
3.2 Optical CONSTANTS OF THIN FILMS. - The optical constants of various materials in the form of thin film $(<300 \AA)$ are of great importance not only in the design of multilayers, but also in the study of the dependence of the optical constants on deposition conditions and methods and in the study of roughness, interdiffusion, etc.

Figure 6 shows the optical constants of Mo film prepared by Tohoku group using an ion-beam sputtering system. The reflectance data used for the analysis were taken for s-polarization at the Photon Factory. In the analysis, the measured data of reflectance $v s$. wavelength were compiled in the form of reflectance $v s$. angle of incidence for every wavelength sampled. The optical constants were, then, determined by means of least-squares curve fitting by taking multiple reflections into account. The film thickness measured by the Tolansky method was used in the initial phase of analysis, and then the film thickness was finely adjusted, within the possible errors in the thickness measurement, until it gave the best fit for all the data available to the analysis.

In figure 6 , two published data points, one at $124 \AA(100 \mathrm{eV})$ by Henke et al. [4] and the other at $210 \AA$ A by Lynch and Hunter [8], are shown by solid circles. The optical constants used in the simulation of reflectance curves by Barbee et al. [9] are also shown at a wavelength of $170 \AA$. A weak structure is clearly seen at about $140 \AA$, whose existence was not known to date. Tohoku group has so far accumulated reflectance data at 9.6-88 deg. angles of incidence over a wavelength range of $225-43 \AA$ for single layers of $\mathrm{Mo}, \mathrm{C}, \mathrm{Al}, \mathrm{Ni}, \mathrm{Rh}, \mathrm{Ru}, \mathrm{LiF}$, and $\mathrm{B}$ prepared by UHV electron-beam deposition, and of $\mathrm{Re}, \mathrm{Mo}, \mathrm{Si}$, $\mathrm{C}, \mathrm{Au}, \mathrm{Ni}, \mathrm{Rh}, \mathrm{Ru}$, and $\mathrm{BN}$ by ion-beam sputtering. Analyses of their optical constants and surface roughness are now under way.

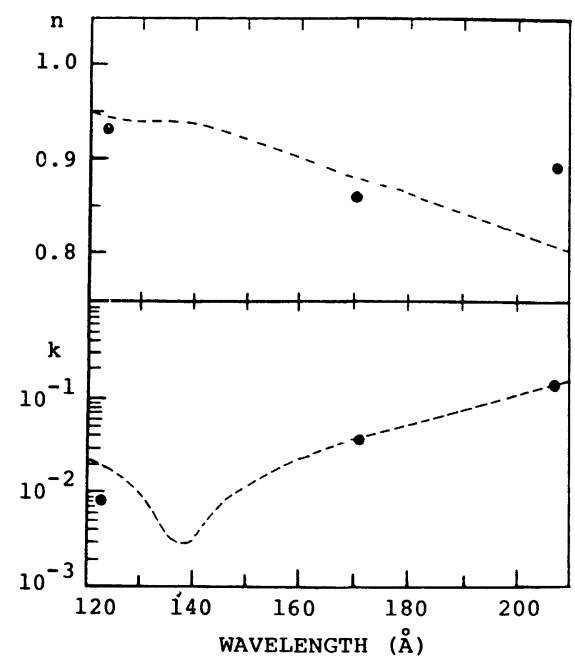

Fig. 6. - Optical constants $(n-i k)$ of Mo film in the XUV region. The solid circles show the values given in references [8] and [9]. 


\section{Fabrication of multilayer mirrors.}

4.1 Polishing OF SUbSTRATES. - It is needless to say that low-scatter supersmooth optical surfaces are essential in the fabrication of multilayer mirrors for soft X-rays. Bowl feed polishing [10] is used by Tohoku group, and surface finish of about $5 \AA \mathrm{rms}$ roughness on BK7 glass has been obtained [11]. Namba of Chubu group invented a better polishing technique called float polishing [12, 13] and constructed special machines [14, 15].

The essential.parts of the new float-polishing machine are schematically shown in figure 7 . The machine is capable of polishing samples of up to $180 \mathrm{~mm}$ in diameter. While the machine is running, the polishing fluid rushes through the small gap between the lap, made of tin, and the workpiece, producing polishing action. The polishing fluid consists of 2 wt. \% of $70 \AA$-diam fumed silica powder

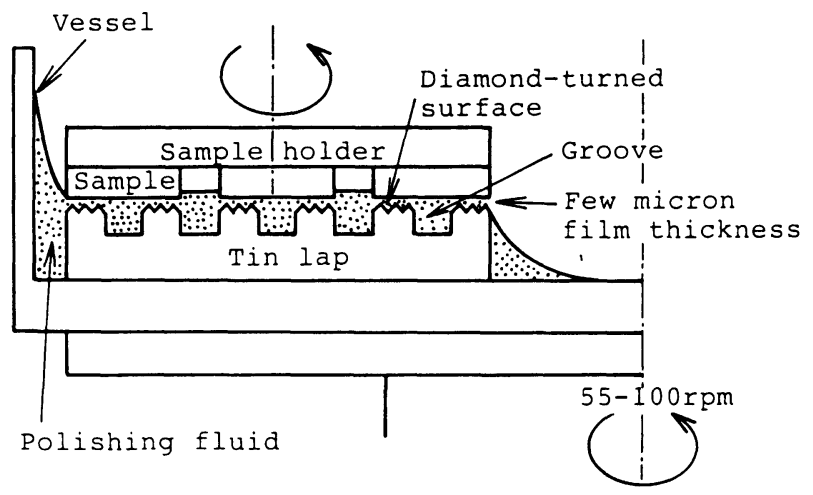

Fig. 7. - Principal structure of float polishing machine (after Ref. [14]).
(Aerosil 300, Degussa Corp.) in filtered deionizedor distilled-water. The key to successful float polishing is the flatness of the tin lap. Since the flatness of the lap is transferred on the surface of the workpiece, the lap should be flat to about $1 \mu \mathrm{m}$ over its entire $46-\mathrm{cm}$ diameter. The micro-grooves on the lap surface also help the polishing fluid to come in contact with the workpiece.

Figure 8 shows the change in flatness of a $100-\mathrm{mm}$ diam Zerodur sample before, during, and after float polishing. This figure illustrates the effectiveness of float polishing. The flatness was measured with a Zygo Mark III interferometer. The surface roughness of a number of samples thus polished has been measured with a Nomarski interference microscope, optical heterodyne profilometer [16], digital profiler [17] (WYKO TOPO-2D), Talystep, laser scatterometer, and X-ray reflectometer [11]. The results of all the measurements, which are based on different principles, are in good agreement with one another, giving the order of $1-2 \AA$ rms surface roughness. Figure 9 shows an example of the surface roughness of a float-polished glass-ceramic sample as measured with a Talystep [18]. An rms roughness of $1.9 \AA$ over a distance of $0.6 \mathrm{~mm}$ is obtained, with an instrumental noise of about $1 \AA$ rms. The best rms roughness so far obtained is $0.8 \AA$ rms over a distance of $1 \mathrm{~mm}$ on a sapphire single crystal [15].

4.2 FABRICATION OF MULTILAYER MIRRORS. UHV electron-beam deposition systems and sputtering systems are currently in use in Japan for the preparation of multilayers. The former is used by Kyoto, Osaka I, and Canon groups and the latter by NTT and Tohoku groups.
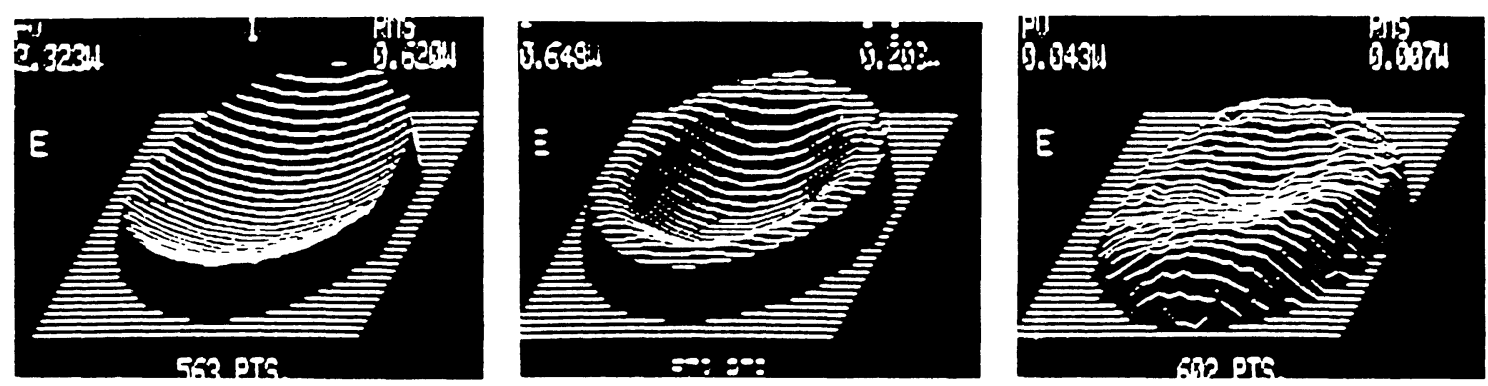

Fig. 8. - Flatness change of a 100-mm Zerodur sample in the float polishing process (after Ref. [14]).

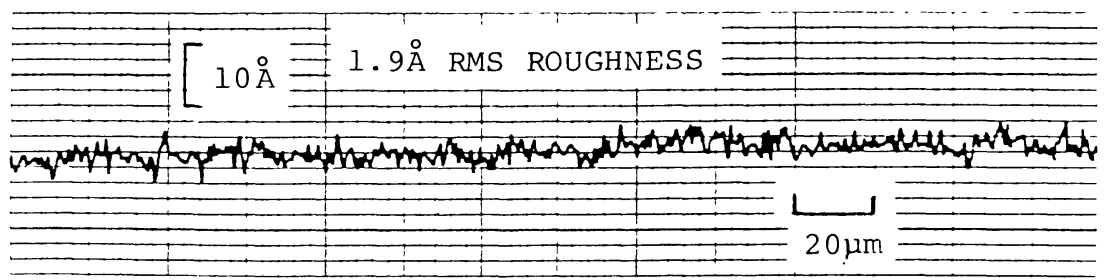

Fig. 9. - Surface profile of a float-polished glass-ceramic sample, measured with a Talystep (after Ref. [14]). 
Kwansei-Gakuin group is looking into the possibility of epitaxial growth of metallic multilayers by molecular beam epitaxy (MBE), in spite of practical difficulties associated with MBE such as substrate heating that might deform the surface of superpolished substrates, a narrow choice in depositing material pairs and substrates that fulfil epitaxial relations. They have prepared by MBE $\mathrm{Nb}(20 \AA) / \mathrm{Ta}(30 \AA)$ multilayers with 60 periods on several kinds of sapphire substrates.

YNMP group is setting up a magnetron sputtering and a photo-CVD system.

\section{A) Electron-beam deposition.}

Kyoto group has prepared many metallic multilayers containing 3d transition metals, such as $\mathrm{Fe} / \mathrm{Sb}$, $\mathrm{Fe} / \mathrm{V}, \mathrm{Fe} / \mathrm{Mg}, \mathrm{Co} / \mathrm{Sb}, \mathrm{Fe} / \mathrm{C}, \mathrm{Mn} / \mathrm{Sb}, \mathrm{Fe} / \mathrm{Mn}$, $\mathrm{Fe} / \mathrm{Dy}, \mathrm{Ag} / \mathrm{V}, \mathrm{V} / \mathrm{Si}$, etc. [19], by using a UHV electron-beam deposition system [20] (see Fig. 10). Multilayers were formed on cooled substrates $\left(\sim-50^{\circ} \mathrm{C}\right)$, made of glass, mylar, etc., in the ultrahigh vacuum ( $\sim 10^{-9}$ Torr). The samples deposited on glass, mylar, and triacetyle cellulose were used for measurements of $\mathrm{X}$-ray diffraction and reflection, Mössbauer absorption and ferromagnetic resonance, and electron microscopy, respectively. Programmable quartz-oscillator thickness-monitors were employed to monitor the layer thickness and to control two pneumatic shutters. The values of layer thickness observed by the monitor are in good agreement with the values determined from X-ray diffraction measurements. As an example, the periods determined by the two methods are compared in figure 11 for the case of $\mathrm{Fe} / \mathrm{Mg}$ multilayers [21]. Difficulty was encountered, however, in de-

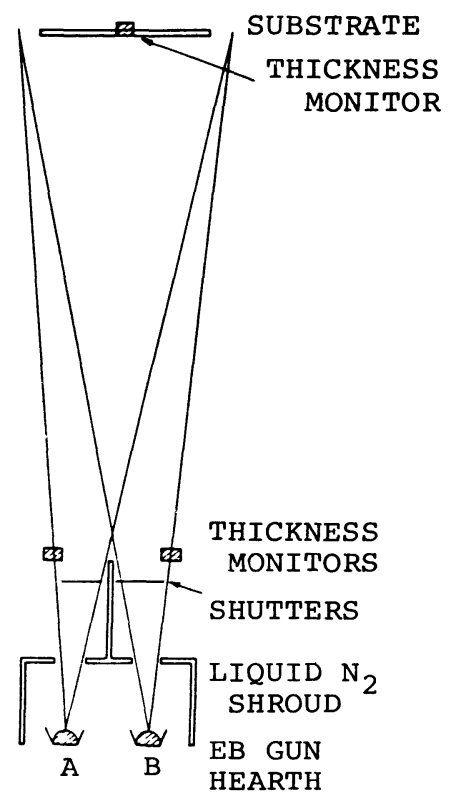

Fig. 10. - Schematic of the UHV electron-beam deposition system (after Ref. [20]).

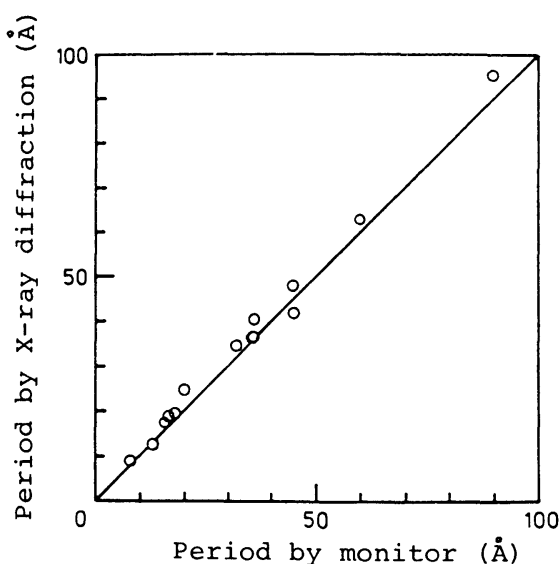

Fig. 11. - Comparison of the periods estimated by a quartz monitor against those determined by X-ray diffraction measurement (after Ref. [21]).

positing carbon. The quartz oscillator was heated up by thermal radiation, and this introduced an error in the thickness determination. The thickness of carbon layers had to be estimated after closing the shutter and waiting for a while until the temperature returned to the room temperature. A typical deposition rate of $\mathrm{Fe}$ is $\sim 0.2 \AA / \mathrm{s}$. A quadrupole mass analyser and an auger electron spectrometer are also incorporated in the deposition system for analysing the residual gases and the surface contamination.

Deposition systems quite similar to the Kyoto group's are used by Osaka and Canon groups. Osaka group I has made $\mathrm{Mo} / \mathrm{Si}, \mathrm{Mo} / \mathrm{C}$, and $\mathrm{Ni} / \mathrm{C}$ multilayers on float glass and float-polished glass $[12,13]$ substrates of $10 \times 10 \mathrm{~cm}^{2}$ with a rms roughness of 2-3 $\AA$ [22]. In their system a movable mask system is mounted immediately below the sample holder so as to permit the preparation of several different multilayers on one substrate without breaking vacuum.

Canon group has prepared $\mathrm{Ru} / \mathrm{Si}$ multilayers on Si substrates of $2^{\prime \prime}($ diam) $\times 10 \mathrm{~mm}$ (thick) having a peak-to-valley roughness of $\sim 30 \AA$.

Tohoku group is testing a UHV electron-beam deposition system equipped with an in situ ellipsometric monitor.

\section{B) Magnetron sputtering.}

NTT group constructed a magnetron sputtering system, which is capable of coating several substrates of the size $4^{\prime \prime}$ in diameter or $70 \times 60 \mathrm{~mm}^{2}$ and prepared W/C multilayers of Si wafers and Pyrex and quartz substrates. The sputtering system is schematically shown in figure 12 . The substrates mounted on the rotating table are alternately exposed to individual well-isolated magnetron sources. The individual sputtering rates and the table rotation speed can be accurately controlled. This system offers the flexibility necessary for the preparation of 


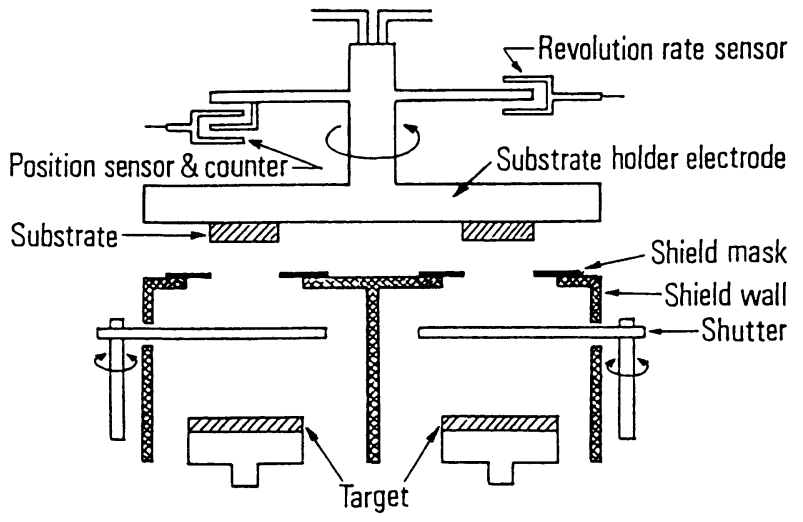

Fig. 12. - Schematic of the magnetron sputtering system (courtesy of NTT group).

multilayers having various layer thicknesses. The individual layer thicknesses are controlled by the deposition rate of the sputtered material, the speed of the rotating table, the source-to-substrate distance, and the open duration of individual shutters. Shield masks are placed between the source and the substrates in order to achieve the uniformity in the layer thickness. The thickness uniformity of a W/C multilayer formed on a 4" $\mathrm{Si}$ wafer was examined by a surface profiler along the direction that coincides with a diametrical direction of the rotating table. The thickness was found to be uniform within $\pm 0.4 \%$ along the direction measured.

C) Ion beam sputtering.

Tohoku group has prepared $\mathrm{Au} / \mathrm{C}, \mathrm{Mo} / \mathrm{Si}, \mathrm{Ni} / \mathrm{C}$, $\mathrm{Re} / \mathrm{C}, \mathrm{Ru} / \mathrm{C}$, and $\mathrm{Rh} / \mathrm{C}$ on polished BK7 glass substrates of $40-\mathrm{mm}$ diam by using an ion beam sputtering system equipped with an in situ ellipsometric monitor [23]. The sputtering system is schematically shown in figure 13. Argon ions produced in the electron cyclotron resonance gun chamber are accelerated by a grid system and form

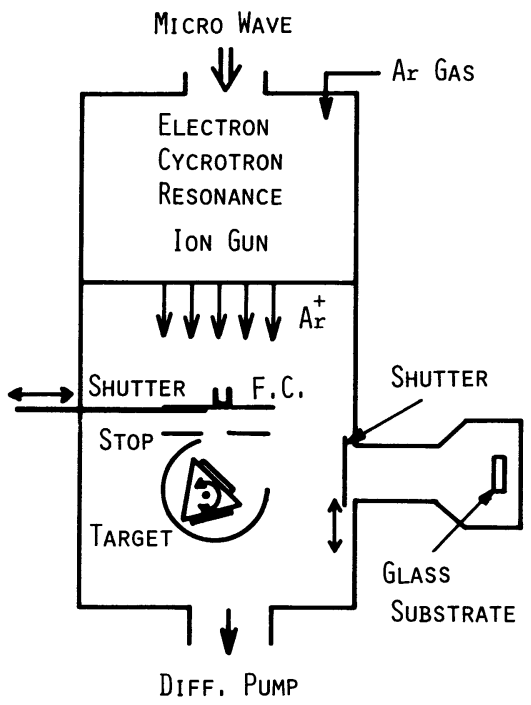

Fig. 13. - Schematic of the ion-beam sputtering system.

uniform ion-shower of $100 \mathrm{~mm}$ in diameter. The maximum acceleration voltage and current density are $2 \mathrm{kV}$ and $1 \mathrm{~mA} / \mathrm{cm}^{2}$, respectively. Ion shower is stopped down to a size to sputter only the target held at an angle of $45 \mathrm{deg}$. to the beam. Three targets can be mounted on a water-cooled prism-shaped holder. Although deposition rates are very slow ( $<1 \AA / \mathrm{min}$ ), the system has the advantage over other sputtering systems: the sample chamber is well isolated from the gun housing and is kept at a pressure of $\sim 3 \times 10^{-4}$ Torr.

The in situ ellipsometric monitor consists of a 1-mW He-Ne laser, a Glan-Thompson polarizer (P), two vacuum windows (V.W.) on the sample chamber, a compensator (C), a Glan-Thompson analyser (A), and a photodetector (see Fig. 14). Azimuthal angles of $\mathrm{P}, \mathrm{C}$, and $\mathrm{A}$ are detected by rotary encoders to $0.005 \mathrm{deg}$. The in situ extinction measurement at the zone 3 can be made automatically by computer-assisted driving and data-acquisi-

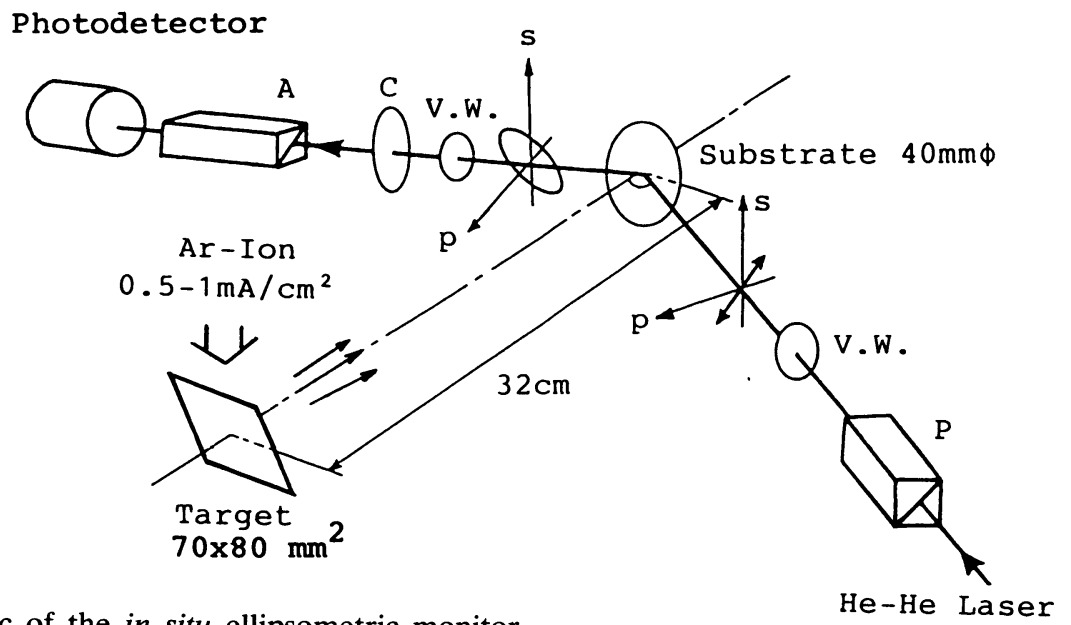

Fig. 14. - Schematic of the in situ ellipsometric monitor. 
tion systems. The thickness sensitivity of the ellipsometer was experimentally found to be much better than $1 \AA$ : e.g., $0.1 \AA$ for $\mathrm{Au}, \mathrm{Pd}$, and Mo, $0.2 \AA$ for $\mathrm{W}$, and $0.8 \AA$ for $\mathrm{Ta}[23]$.

The ellipsometer is a sensitive tool for monitoring the thickness and uniformity of layers during the deposition. The solid curve in figure 15 shows changes in $\rho$, the ratio of the complex amplitude reflectance for the p-component to that for the s-component, which were observed by the ellipsometer during the initial phase of $\mathrm{W}$ deposition on a polished BK7 glass substrate. A simulation curve (dashed line) is also drawn in the figure, for comparison. The numerals beside the open circles are the layer thicknesses at the respective points. As is clearly seen in the figure, the simulation curve fits very well to the observed curve down to the point corresponding to $\sim 30$ - $\AA$ thick W layer. This lower-

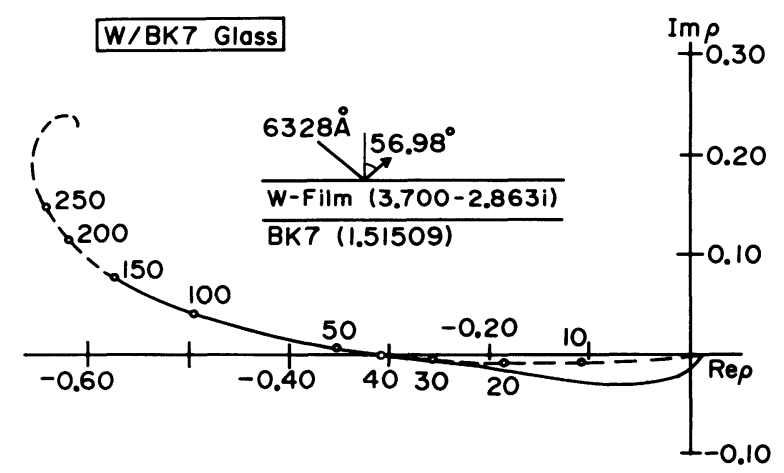

Fig. 15. - Changes in $\rho$ during the deposition of $\mathrm{W}$ on a BK7 glass substrate. Solid and dashed lines are measured and computed curves, respectively. limit thickness $d_{\ell}$ is a good indicator for the formation of a layer which satisfies the assumption of isotropic and parallel-faced layer model. The values of $d_{\ell}$ were found to be $50,35,30,20$, and $\sim 0 \AA$ for $\mathrm{Au}, \mathrm{Pd}, \mathrm{W}, \mathrm{Mo}$, and Ta [23]. Figure 16 shows the observed $\rho$ 's (solid line) during the formation of a 7-layer $\mathrm{Au} / \mathrm{C}$ mirror (layer thicknesses of $A u$ and $C$ are $50 \AA$ ) together with the simulation curve (dashed line). As is expected from a large value of $d_{\ell}$ for $\mathrm{Au}$, the observed $\rho$ 's for the $\mathrm{Au}$ layers deviate by a large amount from the simulation curve at the beginning and then approach very close to the simulation points as the thickness of $\mathrm{Au}$ comes closer to $50 \AA$. This indicates the usefulness of ellipsometry in monitoring the formation of multilayers.

\section{Evaluation of multilayers.}

The overall performance of multilayers for soft $\mathrm{X}$ rays can best be evaluated by their spectral reflectances at the wavelengths of interest. However, spectral reflectance measurements alone do not furnish detailed information on the periodicity, interdiffusion at the interfaces, crystal structure, entrapped gases, surface roughness, interface roughness, etc. In the following subsections are described various methods and techniques employed by the Japanese groups for the characterization of multilayers.

\subsection{STRUCTURAL CHARACTERIZATION.}

A) X-ray diffraction and scattering.

$\mathrm{X}$-ray diffraction is the most widely used technique in the evaluation of multilayer structure, such as surface roughness, interface roughness, periodicity,

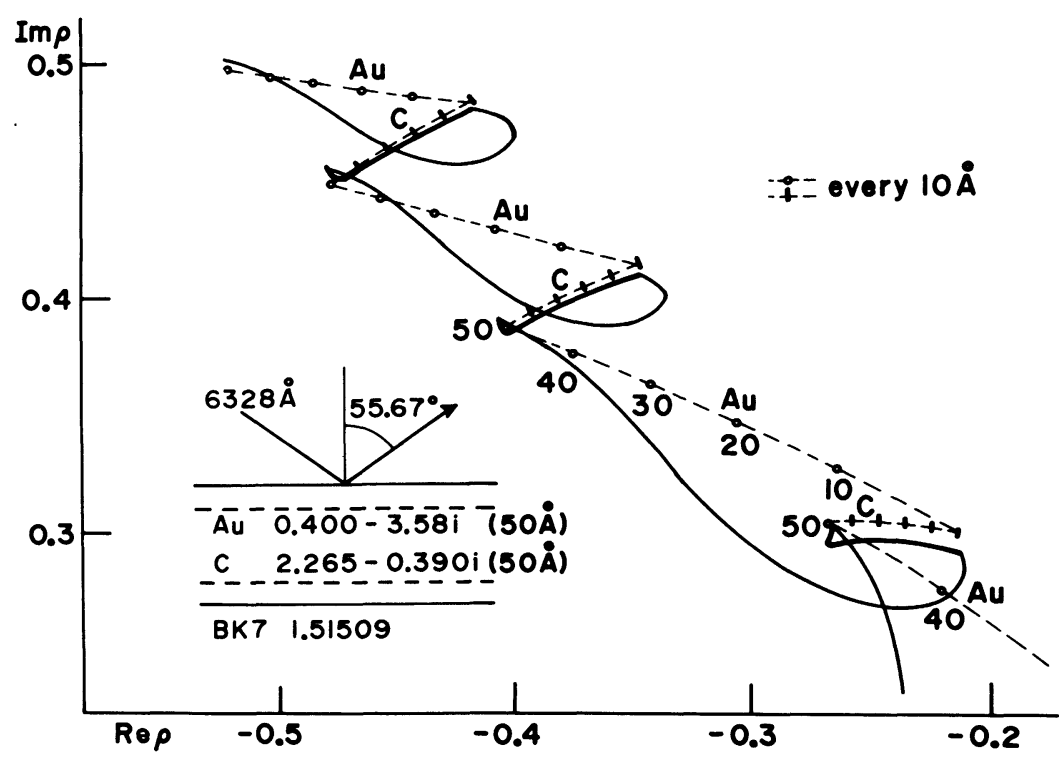

Fig. 16. - Observed and simulated changes in $\rho$ during the formation of a 7-layer $\operatorname{Au}(50 \AA) / \mathrm{C}(50 \AA)$ mirror. Solid and dashed lines are measured and computed curves, respectively. 
etc. We, therefore, restrict ourselves to describe here some methods and results of interest only.

To examine the establishment of periodic structure in a super-thin multilayer, Kyoto group measured Xray diffraction patterns of $\mathrm{Fe}(8 \AA) / \mathrm{Mg}(24 \AA)$, $\mathrm{Fe}(2 \AA) / \mathrm{Mg}(16 \AA ̊ \AA)$, and $\mathrm{Fe}(4 \AA) / \mathrm{Mg}(4 \AA)$ multilayers, using $\mathrm{Cu} \mathrm{K} \mathrm{K}_{\alpha}$ line (1.54 $\AA$ ) [24]. The result shown in figure 17 confirms the existence of periodic structure even in these multilayers, whose Fe layers are of super-thin. The periods estimated from the diffraction-peak angles agree well with the designed periods.

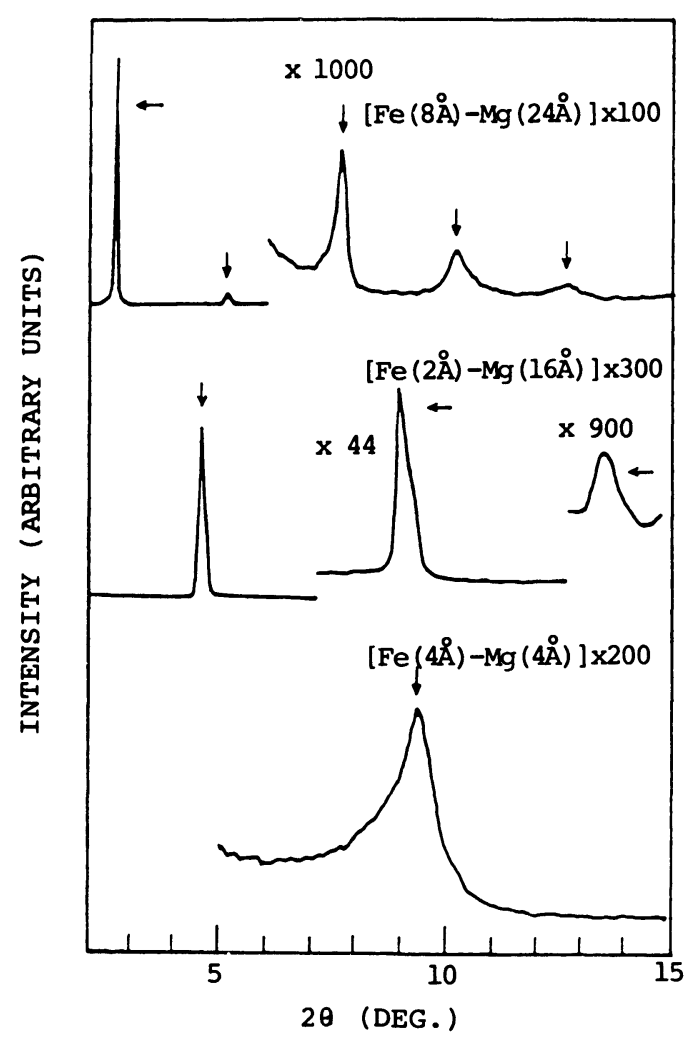

Fig. 17. - X-ray diffraction patterns in a small angle region for $\mathrm{Fe} / \mathrm{Mg}$ multilayers. The layer thicknesses of $\mathrm{Fe}$ and $\mathrm{Mg}$ are denoted in the figure (after Ref. [24]).

Kwansei-Gakuin group measured X-ray diffraction patterns of single crystals of a $\mathrm{Nb}(20 \AA) /$ $\mathrm{Ta}(30 \AA)$ multilayer grown by MBE and determined the epitaxial relations between the component materials and several kinds of sapphire substrates with Mo $\mathrm{K}_{\alpha}$ line [25]. Figure 18 shows the intensity contours with $\mathrm{Cu} \mathrm{K} \mathrm{K}_{\alpha}$ line around the (002) Bragg reflection from the $\mathrm{Nb} / \mathrm{Ta}$ multilayer formed on a sapphire- $R$ (1 102) substrate. As is clearly seen in the figure, the satellite reflections line up in the direction tilted from the [001] axis, implying that the $\mathrm{Nb}$ and $\mathrm{Ta}$ layers have a terraced structure in the interface region. The interdiffusion region at the interfaces is estimated to be about $6 \AA$ from the

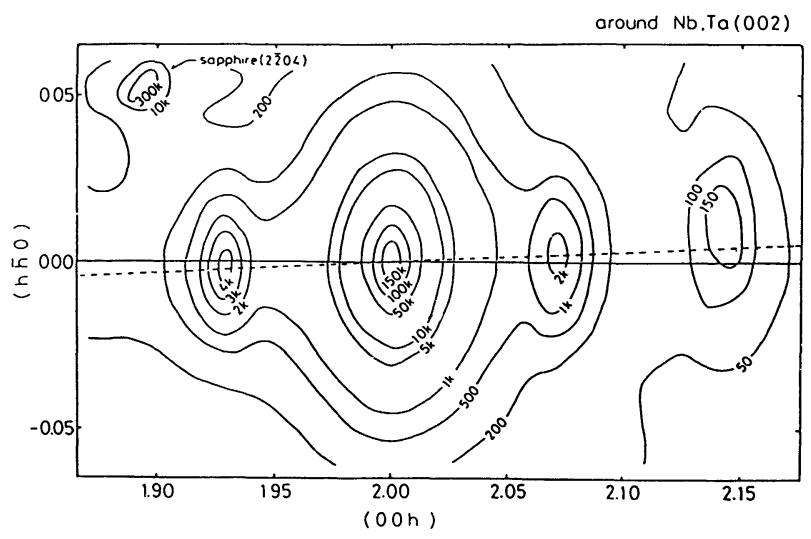

Fig. 18. - Intensity contours of scattered X-ray around the Nb-Ta (002) Bragg reflection. The intensity is expressed in counts. The solid and the dashed line represent the [001] axis of $\mathrm{Nb}$ and $\mathrm{Ta}$ and the direction parallel to the sapphire [1102] axis, respectively (after Ref. [25]).

width of the satellite reflections. The results indicate that a fairly good metallic multilayer is obtained by $\mathrm{MBE}$, in spite of fairly large lattice mismatch between the component materials and the substrate, as is seen in the figure.

NTT group designed a new triple-axis goniometer for large area X-ray diffraction topography capable of utilizing synchrotron X-rays of $3 \times 50 \mathrm{~mm}^{2}$ and installed it on the beamline $15 \mathrm{~B}$ at the Photon Factory [26]. The precision of the third rotation axis is better than $0.01 \mathrm{~s}$ of arc, which is sufficient for most plane-wave work. With this goniometer they carried out preliminary experiments to characterize the structural uniformity of a $70 \times 60-\mathrm{mm}^{2}$ $\mathrm{W}(16 \AA) / \mathrm{C}(24 \AA)$ multilayer with 40 periods, which was formed on an optically flat quartz substrate by means of magnetron sputtering. The experimental arrangement used is schematically shown in figure 19. Using a monochromatic $X$-ray beam of $2 \AA$, they observed a rocking curve of the sample at the first-order diffraction. A half width of $135 \mathrm{~s}$ of

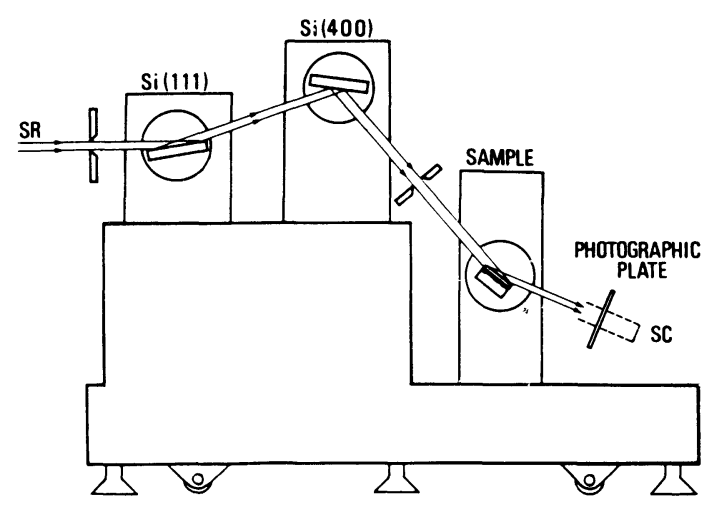

Fig. 19. - Schematic of the triple-axis goniometer system (after Ref. [26]). 
arc was obtained. This shows that the period of the multilayer is uniform within $\pm 2.3 \%$ over the measured area of $70 \times 50 \mathrm{~mm}^{2}$.

The measurement of X-ray scattering has been proved to be a good method for evaluating an X-ray mirror surface [27]. Nagoya group extended the method and succeeded not only in a quantitative evaluation of the rms height as a measure of the surface roughness, but also in a measurement of the power spectral density function, which represents the characteristics of surface wavings [11].

They measured the scattering profiles of $\mathrm{Al}-\mathrm{K}_{\alpha}(8.34 \AA$ ) $\mathrm{X}$-rays for plate glass, float glass, polished BK7 glass, and metal films coated on float glass with a 12-m X-ray beam facility at Nagoya University. A schematic diagram of the facility is shown in figure 20. The angular resolution in the scattered beam experiment was 44-s of arc with the second slit of $0.1 \mathrm{~mm}$ wide. The power spectral density functions of the surface height distribution for these materials, except for the Au-coated sample, were represented by the power-law spectra with power indices ranging from -1 to -2 . The $\mathrm{rms}$ heights were found to be $1.8-8.3 \AA$ for the surface wavings with period lengths of $10-100 \mu \mathrm{m}$. The results thus obtained were consistent with those measured with a WYKO optical profiler (NCP$1000)$. This method was successfully applied also to UPILEX (polyimide produced by Ube Industries, Inc.), $\mathrm{Al}$ foil replica backed by epoxy, and $\mathrm{Mo} / \mathrm{C}$ and $\mathrm{Mo} / \mathrm{Si}$ multilayers [22] to estimate their surface roughness.

B) Transmission electron microscopy.

Transmission electron microscopy has been utilized by NTT and Canon groups, to a varying degree, for the direct characterization of multilayers.
NTT group uses a $400-\mathrm{kV}$ transmission electron microscope to characterize the pe ${ }^{\prime}{ }^{\prime}$ ty and the interfacial structure [28]. Cross-sec al specimens were prepared by means of Ar-ion etching. For precise determination of the periodic length, the specimen was observed by varying its tilt with respect to the electron beam. Electron micrographs thus taken were traced with a microphotometer. The accuracy of period determinations with this method was found to be $\pm 0.15 \AA$. Figure 21 shows an electron micrograph of a W/C multilayer prepared by magnetron sputtering and its microphotometer trace. From this a mean period of $88.6 \AA$ was obtained with a fluctuation of $\pm 1.9 \AA$. This value agrees quite well with the designed value of $90 \AA$.

A detailed observation of the interfacial structure was carried out using thin $(\sim 100 \AA)$ specimens. Figure 22 shows a cross-sectional electron micrograph of a thinned $\mathrm{W}(100 \AA) / \mathrm{C}(60 \AA)$ multilayer. Fluctuations were observed at the interfaces of $\mathrm{Si}$ substrate and $\mathrm{C}$ layer and of $\mathrm{W}$ and $\mathrm{C}$ layers. The average fluctuations were $\pm 1.3 \AA$ with a period of $50 \AA$ at the Si-C interface and $\pm 2.3 \AA$ with a period of $50 \AA$ at the W-C interfaces. Fluctuations at the Si$\mathrm{C}$ interface is probably due to the surface roughness of the Si substrate.

Crystallization of the component layers was further investigated by observing lattice images. Crystallization was not observed in the $C$ layers of 20-1 $000 \AA$ thick. Crystal grains were observed in the $\mathrm{W}$ layers of $100-1000 \AA$ thick. Electron diffraction patterns of these $W$ layers exhibited the same characteristics as those of bulk tungsten. In W layers of 30-60 $\AA$ thick, however, no crystal grain was observed. Electron diffraction patterns of these layers showed crystalline patterns, suggesting the existence of fine crystalline particles in these thin

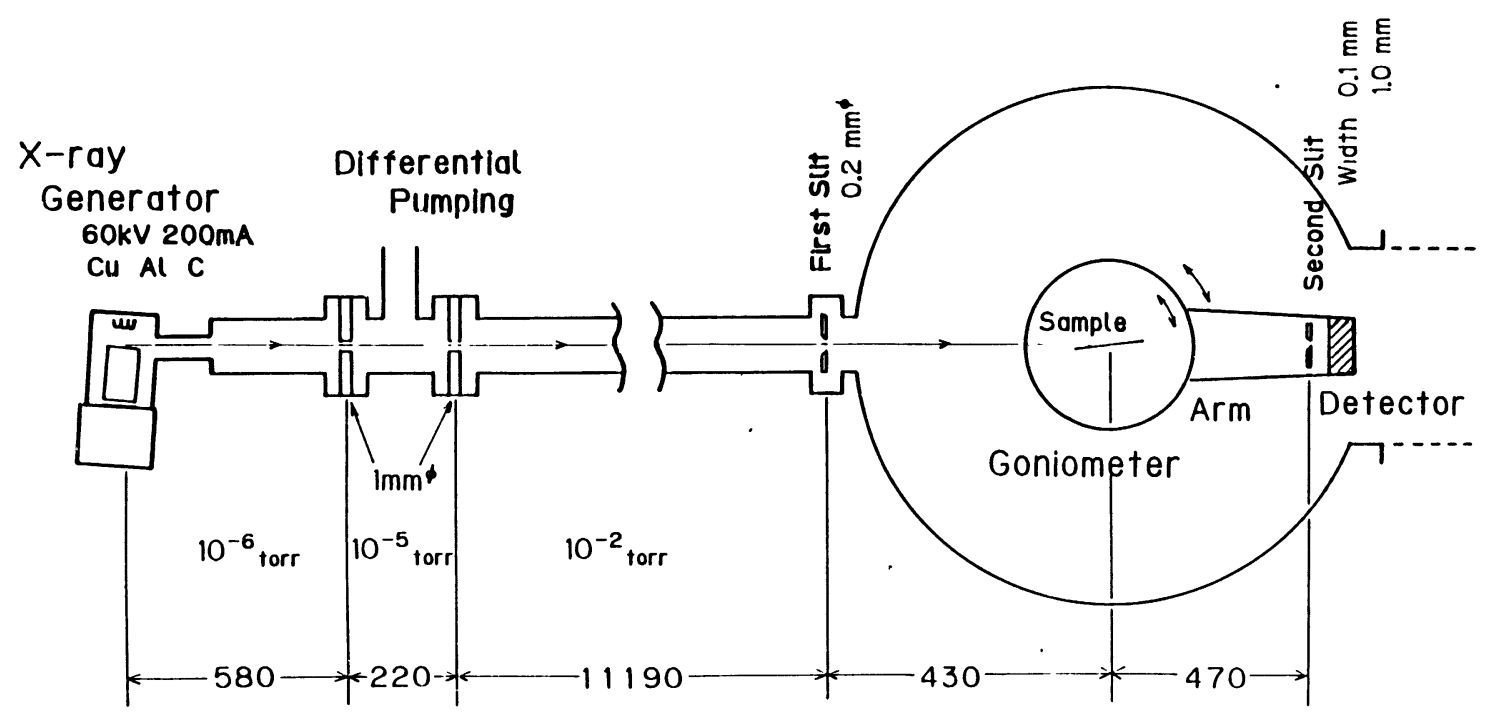

Fig. 20. - Schematic of the 12-m X-ray beam facility at Nagoya University (after Ref. [11]). 


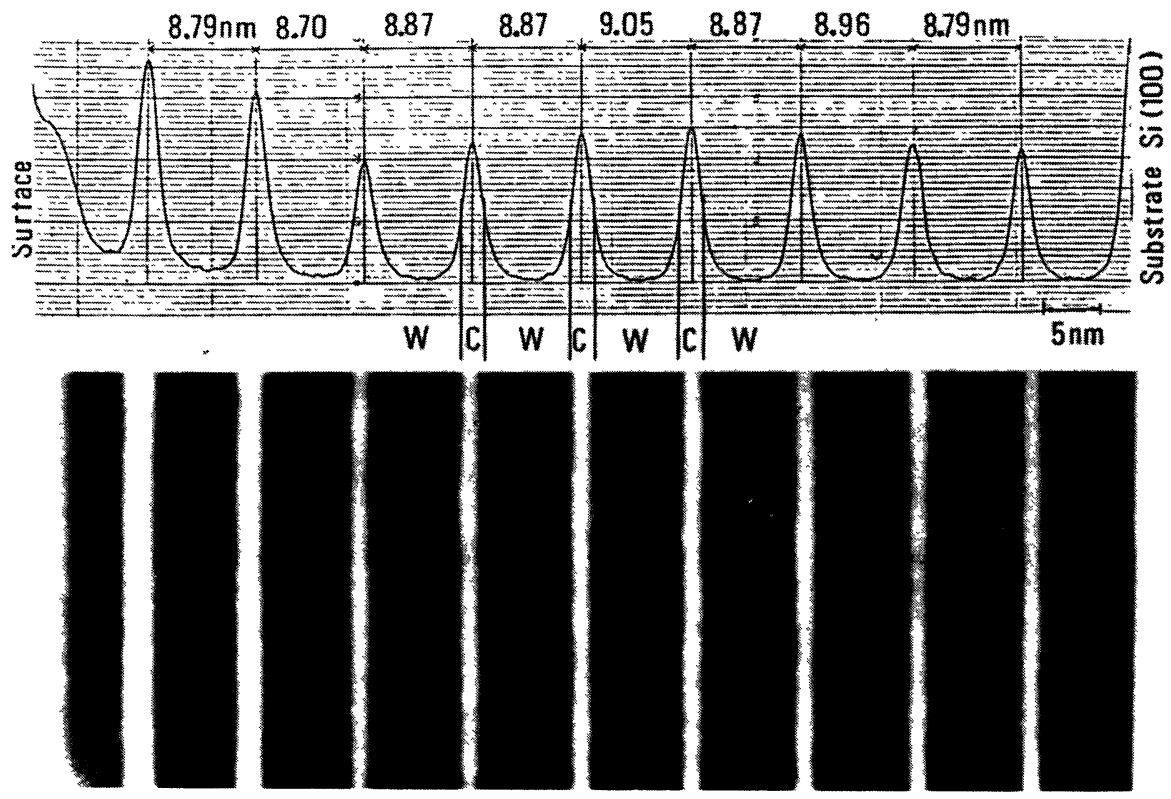

Fig. 21. - Electron micrograph of a W/C multilayer (bottom) and its microphotometer trace (top) (after Ref. [28]).

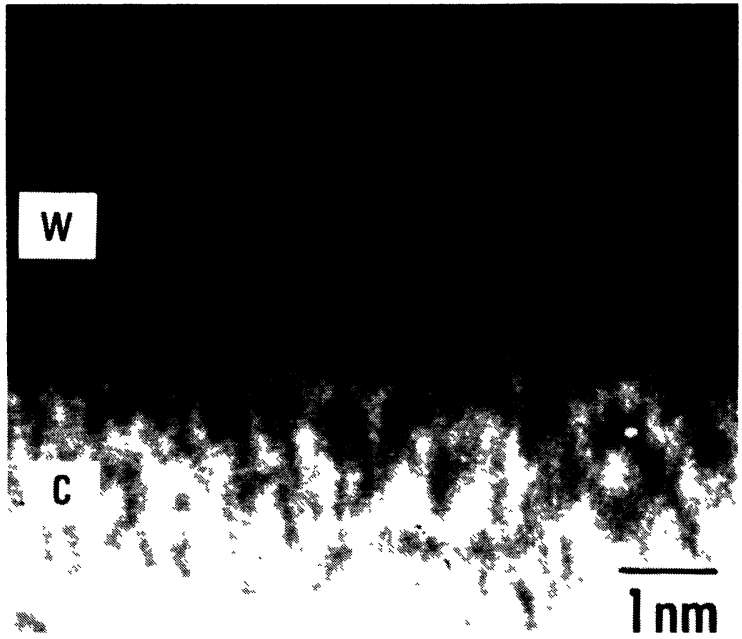

Fig. 22. - Cross-sectional electron micrograph of the interface of a W/C multilayer (after Ref. [28]).

layers. It was found that with a further decrease in the layer thickness tungsten became amorphous and fine crystalline particles were dispersed in the amorphous matrix.

Osaka group II observed, in collaboration with Canon group, the existence of diffusion layers of $\sim 10 \AA$ thick at the Mo-Si interfaces of a Mo/Si multilayer, which was fabricated by ECD, Inc. It was found from electron diffraction patterns that the Si layers were amorphous, whereas the Mo layers were almost completely crystallized.

\section{C) X-ray standing waves.}

$\mathrm{X}$-ray standing wave field is excited in a multilayer as a consequence of interference between the incident and Bragg-reflected beams. The anti-nodal planes lie in between the diffracting planes when the glancing angle of the X-ray beam is slightly below the exact Bragg angle, and continuously move onto the diffracting planes as the glancing angle is scanned to just above the Bragg angle. Fluorescent $\mathrm{X}$-rays become maximum (or minimum) when the antinodal (or nodal) planes coincide with the positions of atoms in the multilayer. Measuring the intensity of fluorescence excited by the standing wave and comparing it with the calculated values, one can determine the position of impurity atoms.

PF group [29] used this method to probe the interlayer distribution of entrapped $\mathrm{Ar}$ atoms in a $\mathrm{W}(12 \AA) / \mathrm{Si}(18 \AA)$ multilayer with 48 layer-pairs on a silicon wafer. The sample was prepared by ECD, Inc. with magnetron sputtering in argon. The period of the multilayer was measured to be $29.56 \AA$ by the $\mathrm{X}$-ray diffraction measurement. They used synchrotron X-ray beam monochromated by a silicon (111) channel-cut crystal to excite fluorescence [30]. Figure 23 shows the angle dependence of the reflectance and intensity of $\mathrm{Ar} \mathrm{K}_{\alpha}(2.96 \mathrm{keV})$ excited in the multilayer by the standing waves of $8.41 \mathrm{keV}$. Comparison of the experimental and calculated curves suggests that the density of Ar atoms in the Si layers is 2-4 times higher than that in the $\mathrm{W}$ layers. The calculation was based on the treatment by Parratt [31]. The averaged density of $\mathrm{Ar}$ atoms was estimated to be in the order of $0.1 \%$.

D) Mössbauer spectroscopy.

Kyoto group has been using Mossbatus rpectroscopy, in combination with X-ray diffraction, etc., for the structural characterization of $\mathrm{Fe} / \mathrm{Mg}$ 


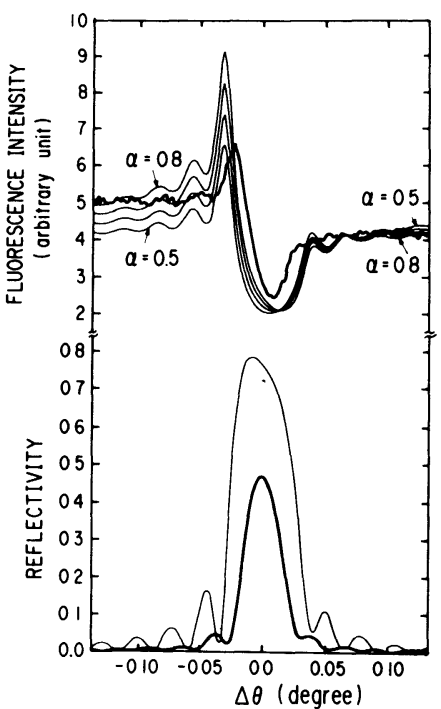

Fig. 23. - Intensity of Ar $\mathrm{K}_{\alpha}$ fluorescence X-rays emitted from entrapped $\mathrm{Ar}$ atoms in a W/Si multilayer. Reflectance is also shown. Thick and thin solid lines are experimental and calculated curves, respectively. $\alpha$ is a parameter for showing that the density of Ar atoms in the Si layers is $\alpha /(1-\alpha)$ times higher than that in the W layers (after Ref. [29]).

and $\mathrm{Fe} / \mathrm{C}$ multilayers, which are of interest in soft $\mathrm{X}$-ray use. It was found from Mössbauer spectra that a structural change occurs in the Fe layers when their thickness is thinner than a critical thickness.

In the case of $\mathrm{Fe} / \mathrm{Mg}$ multilayers, the $\mathrm{Fe}$ layers thicker than $15 \AA$ have bcc structure, whereas the Fe layers thinner than $15 \AA$ have amorphous-like structure [32]. This structural change can be clearly seen in the ${ }^{57} \mathrm{Fe}$ Mössauber absorption spectra shown in figure 24 . The spectrum for $\mathrm{Fe}(15 \AA)$ shows a sharp
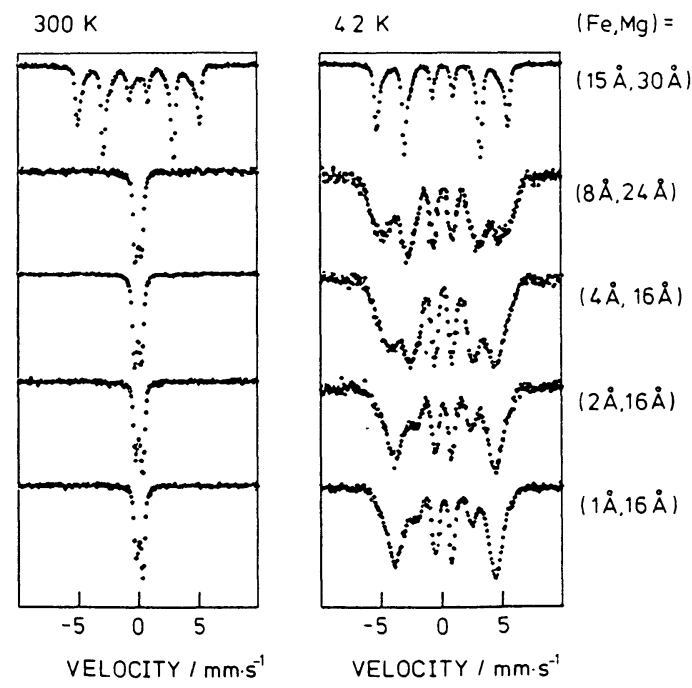

Fig. 24. $-{ }^{57} \mathrm{Fe}$ Mössbauer absorption spectra at $4.2 \mathrm{~K}$ and $300 \mathrm{~K}$. Fe and $\mathrm{Mg}$ layer thicknesses are denoted in the figure (after Ref. [32]). six-line pattern similar to the bulk spectrum. This indicates that most part of $15-\AA \mathrm{Fe}$ layers has bcc structure. When the Fe layer thickness is less than $15 \AA$, the hyperfine field disappears at $300 \mathrm{~K}$, and the spectrum shows a broad split six-line pattern at $4.2 \mathrm{~K}$ indicating the presence of a distributed hyperfine field. The monolayer samples, $\mathrm{Fe}(2 \AA)$ and $\mathrm{Fe}(1 \AA)$, show similar spectra with hyperfine splitting, and no non-magnetic component is observable. These results suggest that the diffusion or mixing of $\mathrm{Fe}$ atoms into the $\mathrm{Mg}$ layer is negligible and that $\mathrm{Fe}(<15 \AA)$ layers have amorphous-like structure.

In the case of $\mathrm{Fe} / \mathrm{C}$ multilayers, the $\mathrm{Fe}(30 \AA)$ layers have bcc structure, whereas the $\mathrm{Fe}(15 \AA)$ and $\mathrm{Fe}(8 \AA)$ layers have amorphous-like structure $[33,34]$. Mössbauer spectra in figure 25 show this structural change, which is quite similar to those of the $\mathrm{Fe} / \mathrm{Mg}$ multilayers. The spectra of $\mathrm{Fe}(15 \AA)$ and $\mathrm{Fe}(8 \AA)$ indicate a structural change of the $\mathrm{Fe}$ layers from bcc-Fe. This change was confirmed also by X-

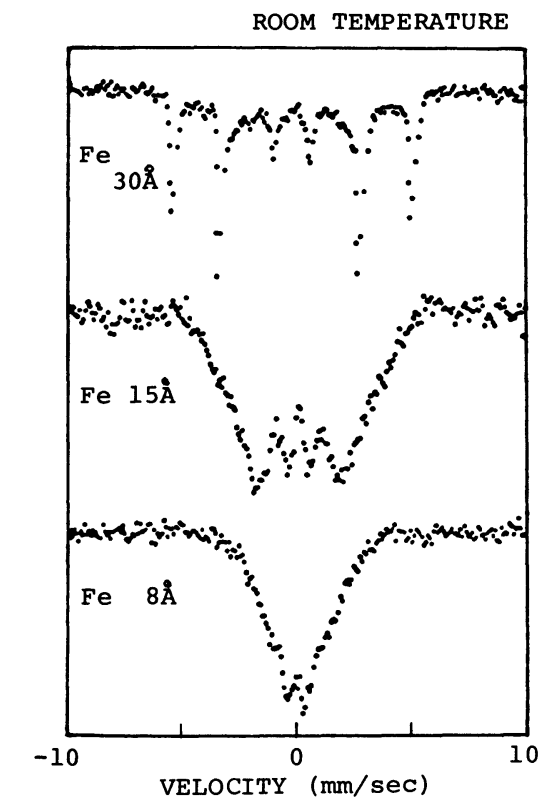

Fig. 25. $-{ }^{57} \mathrm{Fe}$ Mössbauer spectra of samples I (Fe $8 \AA$ ), II (Fe $15 \AA$ ), and III (Fe $30 \AA$ ) at room temperature (after Ref. [33]).

ray diffraction patterns and electron micrographs [33]. If the observed small hyperfine field is caused by bcc-Fe particles of small size, Mössbauer spectra at $4.2 \mathrm{~K}$ should show magnetic splitting corresponding to that of bcc-Fe. It was found experimentally that this is not the case. The detailed study of Mössbauer spectra of various samples shows that amorphous-like carbide layers or ultra-fine carbide particles are formed in the $\mathrm{Fe}(15 \AA)$ and $\mathrm{Fe}(8 \AA)$ layers and that amorphous carbide layers of $\sim 5 \AA$ thick are formed at each $\mathrm{Fe}-\mathrm{C}$ interface [34]. 
5.2 REFLECTANCE MEASUREMENT USING SYNCHROTRON RADIATION. - The overall performance of multilayers can be evaluated by measuring their reflectances as a function of wavelength and angle of incidence. Use of a high-precision reflectometer with synchrotron radiation is best suited to such measurements. At present, such facilities are available at the Photon Factory and the UVSOR.

The Photon Factory provides an UHV reflectometer of high precision with a 2-m grasshopper monochromator (refer to Sect. 3.1 for the detail). The shortest wavelength available for the measurement is $10 \AA$. Unfortunately, this reflectometer cannot be rotated about the incident beam axis. A new reflectometer which has a provision for the rotation is now under adjustment and will be put in service shortly. A reflectometer at the UVSOR can be rotated by 90 deg. and permits measurements down to $75 \AA$ with a plane grating monochromator.

A few examples of reflectance measurements made at the UVSOR and the Photon Factory are shown in figures 26 and 27. Figure 26 shows the peak reflectance $v s$. the angle of incidence measured by Osaka group I at the UVSOR for a multilayer of $\operatorname{Mo}(28.5 \AA) / \operatorname{Si}(66.5 \AA)$ (10 pairs) overcoated with a carbon layer of $100 \AA$ thick [35]. The reflectances of the s- and the p-component show a distinct difference at about $45 \mathrm{deg}$. angle of incidence,

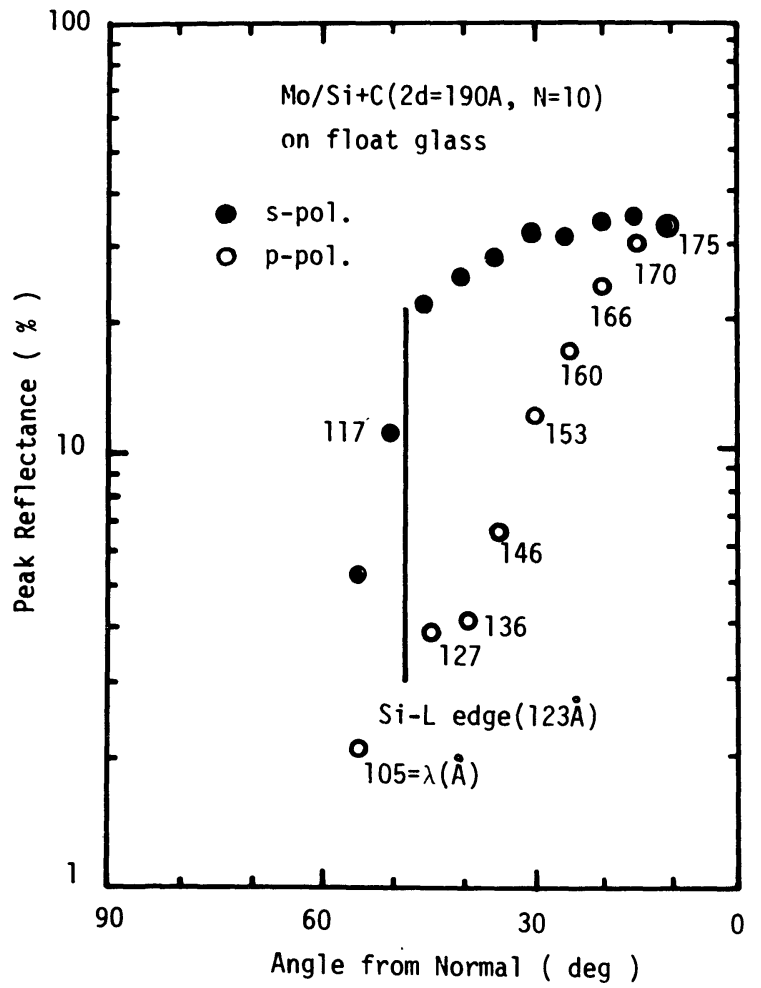

Fig. 26. - Peak reflectance $v s$. angle of incidence for a $\mathrm{Mo} / \mathrm{Si}$ multilayer overcoated with carbon. Wavelengths for the peak reflectances are denoted in the figure (after Ref. [35]).

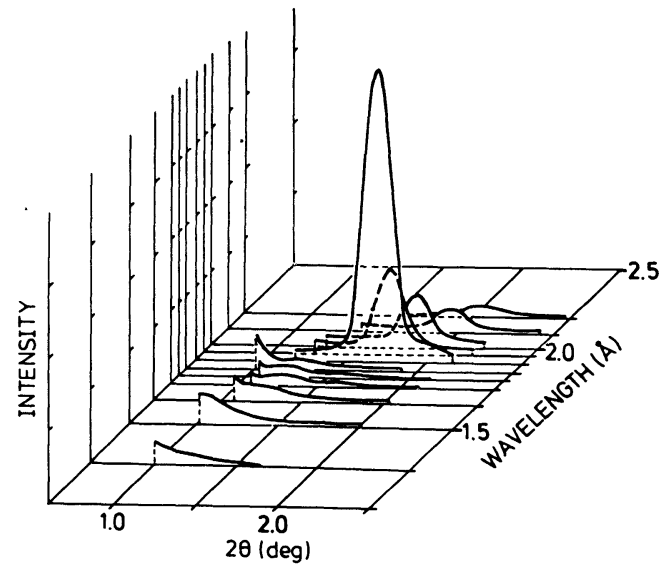

Fig. 27. - Reflection intensity vs. deflection angle $2 \theta$ for a $\mathrm{Fe} / \mathrm{Mg}$ multilayer at wavelengths $1.25-2.3 \AA$ (after Ref. [36]).

indicating a possible application of multilayers to polarizers.

Figure 27 shows the intensity variation of the 1st order reflection from a $\mathrm{Fe}(15 \AA) / \mathrm{Mn}(50 \AA)$ multilayer [36]. The measurement was carried out by Kyoto group at the Photon Factory with X-rays of $1.25-2.3 \AA$ so as to cover the $\mathrm{K}$-absorption edges of Fe $(1.7432 \AA)$ and $\mathrm{Mn}(1.8959 \AA)$. As is clearly seen in the figure, the intensity abruptly increases at about $1.90 \AA$, which corresponds to the Mn K-edge, and then decreases nearly exponentially at longer wavelengths. No anomalous behaviour was, however, observed at the Fe K-edge. This is quite interesting, because $\mathrm{Fe}$ and $\mathrm{Mn}$ have nearly equal atomic numbers and thus $\mathrm{Fe} / \mathrm{Mn}$ multilayers are expected to have a very low reflectance. The reason for the observed enhancement is the effect of anomalous dispersion in the slightly longer wavelength region than the Mn K-edge. Nonappearance of anomaly at the Fe K-edge is due to large absorption by both $\mathrm{Mn}$ and $\mathrm{Fe}$ atoms. A similar intensity enhancement was observed for a $\mathrm{Fe}(15 \AA) / \mathrm{V}(30 \AA)$ multilayer at the $\mathrm{V}$ K-edge $(2.269 \AA)$. These observations confirm the idea of YNMP group and suggest the use of the absorption edge of lower atomic number component of a multilayer to enhance the reflectance.

\section{Applications.}

Various applications are being considered by the research groups : X-ray telescopes by Osaka group I and Nagoya group, optical cavities for XUV lasers by Osaka group II, spectroscopic devices by Tohoku group, for example.

NTT group has made a preliminary experiment on $\mathrm{X}$-ray lithography with a Schwarzschild demagnifying projection optics, whose components were coated with W/C multilayer [37]. The multilayer was designed to have a high reflectance at around a 
wavelength of $110 \AA$ for ease of experiment and prepared by means of ion-beam sputtering. The Schwarzschild optics was tested using synchrotron radiation on the beamline $15 \mathrm{~B}$ at the Photon Factory. The experimental arrangement is illustrated in figure 28. The resist pattern of a wire mesh of $20 \mu \mathrm{m}$ wide thus obtained is shown in figure 29 , as an example. The pattern recorded in PMMA $(0.4 \mu \mathrm{m}$ thick) is the image of the mesh demagnified to $1 / 5$ and shows a $4-\mu \mathrm{m}$ grid. Although the wavelength used was not appropriate for X-ray lithography, the result was quite encouraging.

Nagoya group [38] has been developing a grazing incidence nested thin-foil X-ray telescope, which was originally proposed by Serlemitsos [39], to propose for a future mission of the Japanese X-ray astronomical satellite. The effective area of a grazing incidence telescope is limited by the small critical angle. They considered the use of multilayers as a means of obtaining a large effective area at the energy range of $6-8 \mathrm{keV}$. They made simulations on the performance of the telescope for the two cases : one for mirrors coated with Au single layer and the other for mirrors with $\mathrm{Au} / \mathrm{C}$ bi-layer. Besides these simulations, they measured the reflectance of bilayers, the surface roughness of various thin-foil

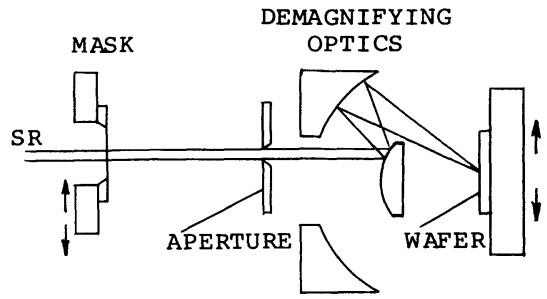

Fig. 28. - Schematic of the Schwarzschild demagnifying projection optics for X-ray lithography experiment (after Ref. [37]).

mirror materials, the accuracy of a pre-engineering model structure for thin-foil nests, etc. Preliminary studies show that multilayers and single layers have their own merit and demerit. Further careful assessments are, therefore, necessary to draw any definite conclusion.

\section{Acknowledgments.}

The author would like to express his sincere thanks to all the members of the groups cited in Introduction for their cooperations in preparing the present article.

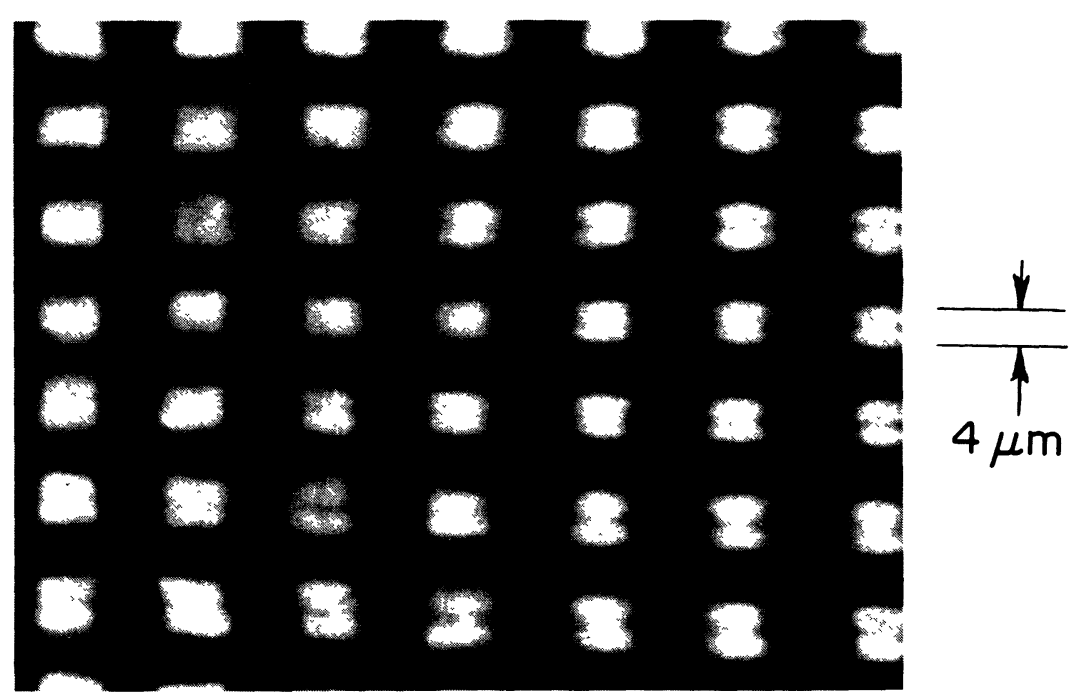

Fig. 29. - Resist pattern of a $20-\mu \mathrm{m}$ wide wire mesh recorded with the arrangement of figure 28 (after Ref. [37]).

\section{References}

[1] Underwood, J. H., Barbee, Jr., T. W., Appl. Opt. 20 (1981) 3027.

[2] Henke, B. L., AIP Conf. Proc. 75 (1981) 146.

[3] Vinogradov, A. V., Zeldovich, B. Ya., Appl. Opt. 16 (1977) 89.

[4] Henke, B. L., Lee, P., Tanaka, T. J., ShimabuKURo, R. L., Fujiwara, B. K., At. Data Nucl. Data Tables 27 (1982).

[5] Yамамото, M., NamiokA, T., in preparation.
[6] Yanagihara, M., Niwano, M., Koide, T., Sato, S., Miyahara, T., IgUchi, Y., Yamaguchi, S., SASAKI, T., Appl. Opt. 25 (1986) 4586.

[7] Yamamoto, M., Arai, A., Watanabe, M., NamioKA, T., Proc. SPIE 688 (1986) 99.

[8] LYNCH, D. W., HunTER, W. R., Handbook of Optical Constants of Solids, Ed. E. Palik (Academic Press, London) 1985, p. 275. 
[9] Barbee Jr., T. W., Mrowka, S., Hettrick, C. Appl. Opt. 24 (1985) 883.

[10] Dietz, R. W., Bennett, J. M., Appl. Opt. 5 (1966) 881.

[11] Kunieda, H., Hayakawa, S., Hirano, T., KiI, T., Nagase, F., Sato, N., Tawara, Y., Mikino, F., Yamashita, K., Jpn J. Appl. Phys. 25 (1986) 1292.

[12] Namba, Y., Tsuwa, H., Ann. CIRP 26/1 (1977) 325.

[13] Namba, Y., Tsuwa, H., Ann. CIRP 27/1 (1978) 511.

[14] NAMBA, Y., TsUWA, H., WADA, R., to be published in Ann. CIRP 36/1 (1987).

[15] Bennett, J. M., Shaffer, J. J., Shibano, Y., NAMBA, Y., Appl. Opt. 26 (1987) 696.

[16] Sommargren, G. E., Appl. Opt. 20 (1981) 610.

[17] Wyant, J. C., Proc. SPIE 525 (1985) 174.

[18] Bennett, J. M., DanCy, J. H., Appl. Opt. 20 (1981) 1785.

[19] SHINJO, T., et al., Metallic Superlattices ; Artificially Structured Materials, Eds. T. Shinjo and T. Takada (Elisevier Sci. Publ., Amsterdam), to be published, and the references therein.

[20] Shinjo, T., Hosoito, N., Kawaguchi, K., TaKaDA, T., ENDOH, Y., AJIRO, Y., Friedt, J. M., J. Phys. Soc. Jpn 52 (1983) 3154.

[21] Kawaguchi, K., Yamamoto, R., Hosorto, N., Shinjo, T., Takada, T., J. Phys. Soc. Jpn 55 (1986) 2375.

[22] Miyake, A., M. S. Thesis, Osaka University (March, 1987).

[23] Yamamoto, M., Arai, A., Shibata, H., Namioka, T., Conf. Dig. ICO-13, Sapporo 1984, p. 626.

[24] Shinjo, T., Kawaguchi, K., Yamamoto, R., Hosoito, N., Takada, T., Solid State Comm. 52 (1984) 257.
[25] Nishihata, Y., Nakayama, M., Kato, H., Sano, N., Terauchi, H., J. Appl. Phys. 60 (1986) 3523.

[26] TAKenaKa, H., TAKaOKA, H., IshiI, Y., SAKaTA, O., Minato, I., Hashizume, H., Kawata, H., Photon Factory Activity Rep. 1986, p. 324.

[27] De Korte, P. A. J., Laine, R., Appl. Opt. 18 (1979) 236

[28] Takaoka, H., IshiI, Y., Proc. XIth. Cong. Electron Microscopy (Kyoto) 1986, p. 1467

[29] Matsushita, T., IIDA, A., IshiKawa, T., NAKAGIRI, T., SAKAI, K., Nucl. Instrum. Methods A 246 (1986) 751.

[30] IIDA, A., Matsushita, T., IshiKawa, T., Jpn J. Appl. Phys. 24 (1985) L675.

[31] Parratt, L. G., Phys. Rev. 95 (1954) 359.

[32] Kawaguchi, K., Yаmamoto, R., Hosoito, N., Shinjo, T., Takada, T., J. Phys. Soc. Jpn 55 (1985) 2375.

[33] Nakayama, N., Katamoto, T., Shinjo, T., TakaDA, T., Bull. Inst. Chem. Res. (Kyoto Univ) 64 (1986) 170.

[34] Nakayama, N., Katamoto, T., Shinjo, T., in preparation.

[35] YAMASHITA, K., in preparation.

[36] Nakayama, N., Moritani, I., Shinjo, T., FujiI, Y., SASAKI, S., to be submitted to J. Phys. France.

[37] Kinoshita, H., Kaneko, T., TAKei, H., TaKeUchi, N., Ishihara, T., Abstr. Autumn Meeting of Jpn Soc. Appl. Phys. (1986) p. 322.

[38] Kunieda, H., Rep. Res. Project, Grant-in-Aid for General Sci. Res. B 58460015, 1986.

[39] Serlemitsos, P. J., IEEE Trans. Nucl. Sci. NS-31 (1984) 786. 